OPEN ACCESS

Edited by:

Sanjay Pandey,

University of Delhi, India

Reviewed by:

Prachaya Srivanitchapoom, Mahidol University, Thailand Rukmini Mridula Kandadai, Nizam's Institute of Medical

Sciences, India

*Correspondence: Mandar Jog

Mandar.Jog@/hsc.on.ca

Specialty section:

This article was submitted to Movement Disorders,

a section of the journal

Frontiers in Neurology

Received: 27 August 2020 Accepted: 30 September 2020 Published: 05 November 2020

Citation:

Ganguly J and Jog M (2020)

Tauopathy and Movement Disorders-Unveiling the Chameleons and Mimics.

Front. Neurol. 11:599384. doi: 10.3389/fneur.2020.599384

\section{Tauopathy and Movement Disorders-Unveiling the Chameleons and Mimics}

\author{
Jacky Ganguly and Mandar Jog* \\ Movement Disorder Centre, London Health Sciences Centre, University of Western Ontario, London, ON, Canada
}

The spectrum of tauopathy encompasses heterogenous group of neurodegenerative disorders characterized by neural or glial deposition of pathological protein tau. Clinically they can present as cognitive syndromes, movement disorders, motor neuron disease, or mixed. The heterogeneity in clinical presentation, genetic background, and underlying pathology make it difficult to classify and clinically approach tauopathy. In the literature, tauopathies are thus mostly highlighted from pathological perspective. From clinical standpoint, cognitive syndromes are often been focussed while reviewing tauopathies. However, the spectrum of tauopathy has also evolved significantly in the domain of movement disorders and has transgressed beyond the domain of primary tauopathies. Secondary tauopathies from neuroinflammation or autoimmune insults and some other "novel" tauopathies are increasingly being reported in the current literature, while some of them are geographically isolated. Because of the overlapping clinical phenotypes, it often becomes difficult for the clinician to diagnose them clinically and have to wait for the pathological confirmation by autopsy. However, each of these tauopathies has some clinical and radiological signatures those can help in clinical diagnosis and targeted genetic testing. In this review, we have exposed the heterogeneity of tauopathy from a movement disorder perspective and have provided a clinical approach to diagnose them ante mortem before confirmatory autopsy. Additionally, phenotypic variability of these disorders (chameleons) and the look-alikes (mimics) have been discussed with potential clinical pointers for each of them. The review provides a framework within which new and as yet undiscovered entities can be classified in the future.

Keywords: tauopathy, movement disorders, chameleons, mimics, MAPT

\section{INTRODUCTION}

Tauopathies are a heterogeneous group of neurodegenerative disorders, pathologically characterized by neuronal and/or glial inclusions of the microtubule-binding protein, tau. Heterogeneity spans many domains from the clinical presentation, anatomical localization, genetic variations, and radiological and pathological signs. Neuroanatomical vulnerability may be a key to the heterogeneity (the concept of "molecular nexopathies") (1). Many factors can be implicated including "strain" specificity of the tau protein, biochemical property of the abnormal protein according to its post-translational modification, "prion-like" propagation capacity, interaction with other co-existent proteins like alpha-synuclein or TDP43, seeding or "permissive templating" property, intrinsic vulnerability of the affected structure, genetic, and epigenetic factors and environmental influences $(1,2)$. 
The spectrum of tauopathy is still unfolding and transcending beyond the domain of primary tauopathies. While secondary tauopathy from autoimmune insult like in anti-IgLON5 disease brings up the topic of complex interaction between autoimmunity and neurodegeneration (3), geographically isolated tauopathies highlight the environmental impact. Apart from this, some novel tauopathies are also increasingly being described in the literature (4).

Clinically, tauopathies present as movement disorders, dementia, and motor neuron disease, either in isolation or in varied combinations (5), based on the vulnerable anatomical structures being affected by the pathological protein accumulation. In terms of genetics, MAPT gene containing $\mathrm{N}$ terminal domain $(\mathrm{N} 1, \mathrm{~N} 2)$ and microtubule binding domain (R1, R2, R3, R4), on chromosome 17q21 encodes the protein tau. Due to alternative splicing of the MAPT gene, three repeat $(2 \mathrm{~N} 3 \mathrm{R}$, $1 \mathrm{~N} 3 \mathrm{R}, 0 \mathrm{~N} 3 \mathrm{R})$ or four repeat $(2 \mathrm{~N} 4 \mathrm{R}, 1 \mathrm{~N} 4 \mathrm{R}, 0 \mathrm{~N} 4 \mathrm{R})$ tau isoforms are formed (6). On the other hand, depending upon numerous single nucleotide polymorphisms (SNPs) and a 900kb inversion, $\mathrm{H} 2$ and $\mathrm{H} 1$ haplotypes of MAPT gene are formed and have impact on the phenotypic presentation (7).

In the literature, tauopathy has been discussed mostly as a pathological entity with its detailed pathological intricacies. Pathological confirmation of the diagnosis of tauopathy mostly depends on autopsy findings. However, pathological diagnosis is often confounded by the presence of multiple other proteins and thus it becomes difficult to determine whether the accumulated tau is pathological or an innocent bystander. In vivo biomarkers like CSF tau and tau-PET imaging are still research-based tools. Additionally, each of these tauopathies has some clinical and radiological signature that can predict the underlying genetics and pathology.

In order to clarify this complexity of heterogeneity of tauopathies, in this review, we have approached tauopathy from a clinical standpoint highlighting mainly the movement disorder perspective, focused on the clinical presentations (chameleons) and their phenotypic look-alikes (mimics). A critical review of the current status of the classification of tauopathies will be followed by the clinical spectrum of primary, secondary, and geographically isolated tauopathies to understand the heterogeneity. Potential clinical and radiological clues will be discussed for each of them. Finally, a practical approach is presented to guide the clinician in day to day practice. Specifically, the phenotype of familial frontotemporal dementia with parkinsonism has been clinically dissected further at the end, because it is one of the commonest overlapping phenotypes of tauopathies.

\section{CLASSIFICATION OF TAUOPATHIES - CURRENT STATUS AND PITFALLS}

Tauopathies have been conventionally classified from a pathological perspective into two groups-(A) Primary tauopathies where tau is the predominant pathology including three repeat (3R-) and four repeat (4R-) tauopathies, (B)
Secondary tauopathies where additional etiologies (e.g., amyloid, trauma, and autoimmune) are involved for tau deposition (Figure 1) (8). However, some tauopathies are geographically isolated like Guadeloupean parkinsonism (9), Western pacific amyotrophic lateral sclerosis and parkinsonismdementia complex (ALS/PDC) (10), and Nodding syndrome of northern Uganda (11). While exact etiopathogenesis of these geographically isolated tauopathies are still unknown, environmental impact (discussed later) has been highlighted in many studies. Thus, whether to include them in the group of secondary tauopathies or not, is still a matter of debate.

Recently, Hõglinger et al. (12) have highlighted syndromic classification of tauopathy based on the predominant domain affected (cognitive or motor):

1. Cognitive syndromes: Behavioral variant of frontotemporal dementia (bvFTD), non-fluent agrammatic variant of primary progressive aphasia (nfavPPA), semantic variant of primaryprogressive aphasia (svPPA), and amnestic syndrome of hippocampal type (AS).

2. Motor syndromes: Richardson syndrome (RS), Parkinson syndrome $(\mathrm{P})$, corticobasal syndrome (CBS), primary gait freezing (PGF), cerebellar syndrome (C), and primary lateral sclerosis (PLS).

However, a primary tauopathy like progressive supranuclear palsy (PSP) or corticobasal degeneration (CBD) can present with different cognitive and motor syndromes (chameleons) and many a times there is phenotypic overlap of cognitive and motor syndrome like in familial FTD with parkinsonism linked to MAPT (FTDP-17).

Apart from these, tauopathies can be classified based on the etiology like genetic (e.g., MAPT related), autoimmune (e.g., anti IgLON5 related), traumatic (e.g., chronic traumatic encephalopathy), etc. It can also be classified based on the area of brain predominantly involved like frontal cortex (e.g., behavioral variant frontotemporal dementia/bvFTD, progressive supranuclear palsy-frontal variant/PSP-F), parietal cortex (e.g., corticobasal syndrome/CBS), peri-sylvian (e.g., progressive nonfluent aphasia/PNFA), limbic (e.g., argyrophilic grain disease/AGD), brainstem (e.g., progressive supranuclear palsyRichardson's type/PSP-RS, anti IgLON5 related), or cerebellum (e.g., PSP-C).

\section{Primary 4R- and 3R-Tauopathies}

In this large group of primary tauopathies, CBD, GGT, AGD, and $\mathrm{PiD}$ are primarily pathological diagnosis where as corticobasal syndrome (CBS) is a clinical term. PSP can be described as both, a pathological or a clinical entity. In this review, PSP and CBS have been discussed with their phenotypic presentations (chameleons) and look-alikes (mimics). PNFA/PPA-G has also been discussed because it is primarily a clinical diagnosis and its pathology is mostly FTLD-tau. In the literature, GGT, AGD, and PiD have been traditionally discussed from a pathological standpoint. We have highlighted the clinical and radiological clues for suspecting GGT, AGD, and PiD clinically before confirmatory autopsy. We have sub-classified primary tauopathies according to the predominant clinical presentation like, movement disorder (PSP, 


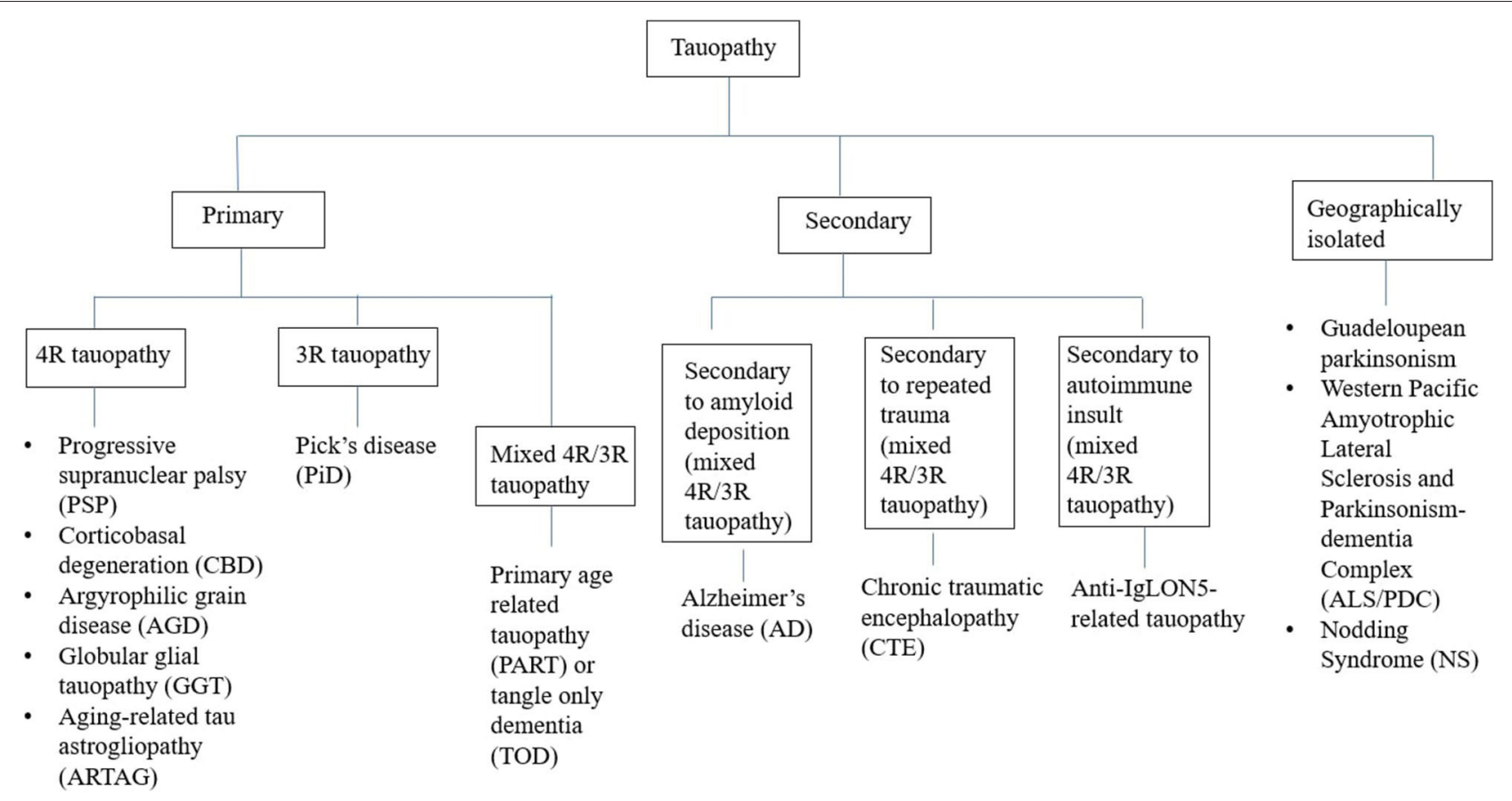

FIGURE 1 | Classification of tauopathies.

CBS), language dysfunction (PNFA) and cognitive dysfunction or mixed (GGT, AGD, and PiD). However, movement disorders can be associated with the second and the third subtype in varied proportions.

\section{Predominant Movement Disorder Presentation \\ Progressive Supranuclear Palsy (PSP)}

Axial rigidity, facial dystonia, retrocollis, vertical supranuclear gaze palsy (VSGP), early postural instability, and pseudobulbar palsy are clinical pointers for classic PSP or Richardson's phenotype (PSP-RS). Apart from this, PSP can have varied phenotypic presentations (chameleons) like parkinsonian type (PSP-P), progressive gait freezing (PSP-PGF), etc. (Table 1) (1315). According to the latest MDS criteria, four core clinical features should be assessed for varying levels of certainty for PSP pathology: (i) oculomotor dysfunction (e.g., VSGP, slow vertical saccades, square wave jerks, and eyelid apraxia), (ii) postural instability within 3 years (e.g., spontaneous loss of balance, unprovoked falls, tendency to fall on pull-test), (iii) akinesia (e.g., progressive gait freezing, akinetic rigid, predominantly axial parkinsonism), and (iv) cognitive dysfunction (e.g., nonfluent aphasia, apraxia of speech, frontal cognitive/behavioral presentation) (16). Levodopa resistance ( $<30 \%$ improvement of the MDS UPDRS III score on a levodopa challenge), dysphagia, hypokinetic spastic dysarthria and photophobia are useful suggestive features of PSP (16). Dorsal midbrain atrophy is the characteristic radiological finding leading to "Morning glory," "Mickey Mouse" signs on axial MR images and "Hummingbird," "Penguin silhouette" signs on sagittal MR images (17). Midbrain/Pons $(\mathrm{M} / \mathrm{P})$ ratio < 0.52 , midbrain AP diameter measurement $<9.35 \mathrm{~mm}$ (18), MR Parkinsonism Index $(\mathrm{MRPI})>13.55$ (19), and MRPI $2.0>2.18$ for PSP$\mathrm{P},>2.50$ for PSP-RS (20) are other helpful radiological signs. MAPT H1 haplotype, specially H1c sub-haplotype and recently described $\mathrm{H} 1 \mathrm{~d}, \mathrm{H} 1 \mathrm{~g}$, and $\mathrm{H} 1 \mathrm{o}$ sub-haplotypes of MAPT are associated with increased risk of PSP. Classic PSP pathology is characterized by "tufted astrocytes" and "globose" neurofibrillary tangles. Predominantly PSP pathology is seen in the progressive gait freezing phenotype (PSP-PGF) and in Richardson's phenotype (PSP-RS), whereas in the other variants of PSP, the pathology is often mixed or of non-PSP pathology (21). Alzheimer's disease (AD) pathology and argyrophilic grains (AG) are commonly associated co-pathologies (22). Overall, the phenotypic presentation of PSP depends on the brain area that is more vulnerable to the pathological protein accumulation like frontal lobe in PSP-F, parietal lobe in PSP-CBS, temporal lobe in PSP-SL, midbrain in PSP-RS, basal ganglia (post-synaptic striatal) in PSP-P, pons in PSP-PGF and cerebellum in PSP-C (Table 1) $(23,24)$.

\section{Corticobasal Syndrome (CBS)}

Asymmetric parkinsonism, limb dystonia, myoclonus, saccadic apraxia, ideomotor apraxia, cortical sensory deficits, and alien limb phenomena are classic clinical clues for CBS. Like PSP, CBS also has varied phenotypic presentations apart from this classic phenotype. Though in the latest criteria for CBD by Armstrong et al. (30) four phenotypic presentations 
TABLE 1 | Chameleons of PSP and CBS.

\section{Disease entity Phenotypic presentations (Chameleons)}

Progressive $\quad$ PSP-Richardson's syndrome (PSP-RS)

supranuclear palsy

(PSP) $(13,16,25)$

PSP-parkinsonism (PSP-P)

PSP-Progressive gait freezing (PSP-PGF)

PSP-Corticobasal syndrome (PSP-CBS)

PSP-speech/language disorder (PSP-SL) or PSP-PNFA

PSP-frontal variant (PSP-F)

PSP-postural instability (PSP-PI)

PSP-ocular motor (PSP-OM)

PSP-primary lateral sclerosis (PSP-PLS) (28)

PSP-cerebellar ataxia (PSP-C) (29)

Corticobasal syndrome (CBS)
Classic CBS phenotype (CBD-CBS) (30)

Non fluent/agrammatic variant Primary progressive aphasia phenotype (CBD-PNFA) (30)

Frontal behavioral-spatial syndrome (FBS/ CBD-bvFTD) (30)

PSP-RS-like phenotype (PSPS/CBD-RS/CBD-PSP) (30)

Amnestic phenotype (31)

Posterior variants clinically presenting with Posterior cortical atrophy (CBD-PCA), Gerstmann-variant or Balint syndrome (32)

Progressive dysarthria and orofacial apraxia variant (33)

Prominent pseudobulbar effect and dysarthria, emotional lability variant (34)

Progressive conduction aphasia (35)

Frontal-type gait impairment (36)

\section{Clinical clues}

Vertical supranuclear gaze palsy (VSGP), slowing of vertical saccades, early postural instability within 3 years, axial rigidity, retrocollis, hyperactivity of frontalis and procerus muscle ("Reptilian stare," "Procerus sign")

Initially mimics Parkinson's disease (PD), prominent axial symptoms, attenuated response to levodopa, along with VSGP or slow vertical saccade, hypokinesia without decrement, micrographia without decrement in script size (26), freezing of swallowing (27) are helpful clinical clues

Gait ignition failure, start hesitation, progressive freezing of gait (FOG) within 3 years, along with VSGP or slow vertical saccade, stuttering or stammering speech, axial rigidity without appendicular rigidity, fast micrographia, rapid hypophonia, or tachyphemia

VSGP/slow vertical saccade with features of CBS like delayed initiation of horizontal saccade, limb apraxia, dystonia, myoclonus, cortical sensory loss

VSGP or slow vertical saccade with features of PNFA like progressive apraxia of speech (AOS), agrammatism, phonemic errors

VSGP/slow vertical saccade with frontal cognitive/behavioral presentation like apathy, dysexecutive syndrome, reduced phonemic verbal fluency, impulsivity, disinhibition, perseveration

Isolated postural instability within 3 years (repeated unprovoked falls or fall during pull test)

Isolated VSGP/slow vertical saccade/macro square wave jerk or eyelid opening apraxia

PSP phenotype with marked upper motor neuron (UMN) signs (may be a clinical clue for underlying GGT pathology)

Progressive truncal and limb ataxia

Can mimic multisystem atrophy (MSA-C) or idiopathic late onset cerebellar ataxia (ILOA); early falls, VSGP, no dysautonomia, cognitive dysfunction are helpful clinical clues for PSP-C

Asymmetric parkinsonism, limb dystonia, myoclonus, saccadic apraxia, ideomotor apraxia, cortical sensory deficits, alien limb phenomena Apraxia of speech (AOS), agrammatism

Executive dysfunction, disinhibited behavior, personality changes Mimics bvFTD, but with additional visuospatial and visuoconstructive deficits

VSGP or slowing of vertical saccade, axial rigidity, postural instability, early falls

Mimics AD like dementia at onset, additional asymmetric motor/sensory signs, hyperreflexia, gait impairment, parkinsonism, dystonia are clinical clues

Symmetric bi-parietal syndromic presentation with asymmetric progression, progressive visuospatial impairments, fluent aphasia, posterior alien hand, apraxia, agraphia, acalculia, optic ataxia, oculomotor apraxia, simultagnosia with parkinsonism, myoclonus Presents with progressive loss of speech output, orofacial apraxia (OFA) for lower facial and tongue movements, later development of myoclonus, limb apraxia, akinetic-rigid parkinsonism

Presents with spastic dysarthria, pathological laughter/crying, later development of asymmetric rigidity, dystonic posturing

Presents with progressive language problem with preserved fluency and comprehension but with paraphasia and marked impairment in repetitions of words or phrases

Presents with difficulty to initiate gait, imbalance during walking, marked anxiety for falling, upper limb dyspraxia, paratonia, frontal release signs 
have been described, certain other presentations have been reported in the literature (Table $\mathbf{1}$ ). Cognitive presentation of $\mathrm{CBD}$ (CBD-Cog) mimicking bvFTD or AD is an increasingly recognized phenotype with apathy, executive dysfunction, language, and visuospatial problems (37). Asymmetric cortical atrophy predominantly affecting peri-rolandic region, posterior frontal, and parietal lobes (38) is the radiological hallmark of CBS, but the predominant area of atrophy varies with underlying pathology. CBS-CBD and CBS-PSP pathology: focal atrophy involving premotor cortex, posterior superior frontal lobe and supplementary motor area (SMA), CBS-TDP-43, and CBSAD pathology: more widespread gray matter loss, CBS-TDP43 pathology: fronto-temporal involvement (particularly prefrontal cortex) and CBS-AD pathology: temporo-parietal involvement (particularly parietal cortex) (39). In $25-56 \%$ of cases, clinical diagnosis of CBS correlates with classic CBD pathology (CBDCBS) (40). Astrocytic plaques, ballooned, or achromatic neurons and argyrophilic threads are pathological hallmarks of classic CBD pathology. However, CBS phenotype can be associated with various other pathological entities apart from classic $\mathrm{CBD}$ pathology like, AD pathology, PSP pathology, and FTLD-TDP43 pathology (40).

Because of the overlapping phenotypes, whether PSP and CBD are two different disorders or are part of a spectrum, is a matter of debate $(41,42)$. Phenotypically, PSP and CBD pathology both can present as speech/language (SL) dysfunction (agrammatic non-fluent aphasia/speech apraxia), frontal cognitive/behavioral presentation (F), Richardson's syndrome, and corticobasal syndrome (43). Interestingly, if a patient presents with VSGP or slowing of vertical saccade, axial or symmetric limb rigidity or akinesia, limb apraxia, and postural instability, the patient can be classified as PSP-CBS or CBD-PSP. To get rid of this conundrum, Movement Disorder Society (MDS) criteria (2017) for PSP have introduced the novel diagnostic category "probable 4R-tauopathy" for joint clinical recognition of the patients with PSP and CBD pathology and to facilitate the research on $4 \mathrm{R}$-tau targeted therapeutic strategies $(16,44)$. Probable 4R-tauopathy includes "possible PSP with SL" and "possible PSP with CBS" apart from all "probable PSP."

On top of this, vertical gaze palsy can be seen in a lot of other disorders apart from PSP-RS and asymmetric dystonic stiff limb presentation can be seen in other disorders besides CBS. Thus, clinicians should always be aware of these look-alikes ("mimics") of PSP and CBS $(45,46)$ (Table 2).

\section{Predominant Language Dysfunction Presentation}

Progressive Nonfluent Aphasia (PNFA) or Agrammatic Variant of Primary Progressive Aphasia (PPA-G)

PNFA/PPA-G can clinically present with apraxia of speech (AOS), agrammatism, or mixed. AOS manifests as slow, labored, effortful, hesitant speech with inconsistent speech sound error and aprosody. "Groping after the target sound" is characteristic. Patients have difficulty to utter polysyllabic words and sequences of syllables (e.g., "puh-tuh-kuh") (109). Phonemic speech sound errors are more common (110). Errors in grammar mainly affects syntax, function words, use of conjunction and verb
(109). Clinically, PPA-G must be differentiated from the semantic variant $P P A-S$ (single word comprehension and object knowledge is affected with intact repetition, commonly TDP43 pathology) and logopenic variant PPA-L (word finding difficulty with "tipof-the-tongue" hesitation and impaired repetition, commonly $\mathrm{AD}$ pathology) (111). Orofacial apraxia is a common association with PPA-G. Signs of PSP or CBS may arise as the disease evolves (109). Predominately left peri-sylvian atrophy involving left posterior fronto-insular region (inferior frontal gyrus and insula) is seen in MRI brain (111). Around 30\% of the cases are genetic and association with MAPT, PGRN and C9orf72 have been reported (112). PSP pathology is common in AOS variant with more dysarthric presentation and CBD pathology with more sentence comprehension deficit (113). Sometimes PiD pathology, TDP43-A pathology if there is associated ALS (nfvPPA-ALS) or $\mathrm{AD}$ pathology is also seen (112-114).

\section{Predominant Cognitive or Mixed Presentation}

Three other primary tauopathies namely globular glial tauopathy (GGT), argyrophilic grain disease (AGD) and Pick's disease (PiD) present as cognitive or mixed (cognitive and movement disorder overlap). Clinical, radiological, and pathological features of these entities have been described in Table 3.

\section{Secondary Tauopathies \\ Anti IgLON5 Disease}

Anti IgLON5 mediated secondary tauopathy stands at a critical juncture of autoimmunity and neurodegeneration, where deposition of hyperphosphorylated tau (both 3R and 4R) occurs mainly in the hypothalamus, brainstem, and hippocampus. Initially, it was described as an antibody mediated sleep disorder (132, 133). Subsequently, many other phenotypes (chameleons) have emerged and most of the times they overlap (51, 134-137) (Table 4). MRI brain is mostly normal or may show cerebellar, brainstem atrophy (138). Recognition of these clinical phenotypes of anti IgLON5 are necessary because of its treatability with immunomodulators can prevent further neurodegeneration.

\section{Chronic Traumatic Encephalopathy (CTE)}

CTE is mainly a neurocognitive syndrome related to repeated traumatic brain injury (TBI) where both $3 \mathrm{R}$ - and $4 \mathrm{R}$ - tau deposition is seen (like AD). TBI likely ignites a vicious cycle of neuroinflammation and tau phosphorylation, deposition (139). Susceptibility depends on multiple factors like carrying ApoE4 allele, cognitive reserve, etc. It was initially described in boxers and named as "punch-drunk syndrome" or "dementia puglistica." Subsequently, the disease got noticed among athletes like football players and war veterans. Gardner et al. (140) has classified the older ones as "classic CTE" (parkinsonism followed by cognitive symptoms) and the recent ones as "modern CTE" (behavioral symptoms affecting mood/affect followed by cognitive symptoms). From clinical perspective, Jordan et al. (141) have divided CTE into three phenotypes: (1) Behavioral and psychiatric (aggression, impulsivity, delusions, depression, suicidality) that can mimic bvFTD; (2) Cognitive (affecting attention, executive, memory, 
TABLE 2 | Mimics of PSP and CBS.

\begin{tabular}{ll}
\hline Clinical entity & Look-alikes (Mimics) \\
\hline $\begin{array}{l}\text { Progressive } \\
\text { supranuclear palsy } \\
\text { (PSP) (for classic } \\
\text { PSP-RS with VSGP) }\end{array}$ & Niemann-Pick type C (NPC) $(47$, \\
& $\begin{array}{l}\text { Anti Ma2 related paraneoplastic } \\
\text { syndrome }(49,50)\end{array}$ \\
& $\begin{array}{l}\text { Anti lgLON5 related autoimmune } \\
\text { disease }(51,52)\end{array}$ \\
& $\begin{array}{l}\text { Anti LGI1 related autoimmune } \\
\text { disease }(53,54) \\
\text { Whipple's disease }(55,56)\end{array}$
\end{tabular}

Frontotemporal lobar degeneration with MAPT gene mutation (FTLD-MAPT) $(57,58)$

Kufor-Rakeb disease (mutations in ATP13A2) $(59,60)$

Mitochondrial disorders (Polymerase gamma/POLG1 gene mutations) (61)

Perry syndrome (mutations in DCTN1, Unexpected weight loss, respiratory problem TDP-43 proteinopathy) (62-64)

Gaucher disease (Type 3) (mutations in GBA) (65)

Prion diseases like familial Creutzfeldt-Jakob disease $(66,67)$ or Gerstmann-Straussler-Scheinker disease (GSS) (mutations in PRNP) $(68,69)$

Cerebral autosomal dominant arteriopathy with subcortical infarcts and leukoencephalopathy (CADASIL) $(70,71)$

Spastic paraplegia type 7 (SPG7) (72-74)

Spinocerebellar ataxia type 2, type 3, type 17 (SCA2, SCA3, SCA17) (75-78)

Autosomal recessive parkinsonism due to Synaptojanin 1 (SYNJ1) gene mutation $(45,79)$

Corticobasal syndrome Frontotemporal lobar degeneration (CBS) with Progranulin gene mutation (FTLD-PGRN) $(57,58)$

\section{Clinical clues}

Splenomegaly, ataxia, dystonia, chorea, cognitive, and psychiatric symptoms, downgaze palsy, epilepsy, history of gelastic cataplexy, usual age of onset earlier than PSP (though can be late onset)

Hypothalamic- pituitary endocrine dysfunction, weight gain, sleep disorders (e.g., hypersomnia, narcolepsy, REM sleep behavioral disorders), rapid progression, history of testicular cancer

NREM and REM parasomnia, gait instability, cognitive impairment with or without chorea, autonomic dysfunction, bulbar dysfunction, sleep apnoea, and stridor

Rapidly progressive dementia, facio-brachial dystonic seizure, hyponatremia, episodic bradycardia, humming Oculomasticatory myorhythmia, dementia, myoclonus, ataxia, history of frequent diarrhea, weight loss, arthralgia

Family history of FTD-parkinsonism

Juvenile onset, spasticity, facial-faucial-finger mini-myoclonus, upgaze palsy, oculogyric crisis, dementia, psychiatric features, levodopa responsive parkinsonism

Deafness, ataxia, epilepsy, migraine, neuropathy, positive family history

(hypoventilation), central sleep apnoea, apathy/depression, family history of parkinsonism or respiratory problems

Hepatosplenomegaly, horizontal > vertical gaze palsy and slow saccade, head thrusts, epilepsy, cognitive decline, usual age of onset earlier than PSP, ataxia, spasticity

Rapid progression, cognitive decline, myoclonus, ataxia

History of migraine, transient ischemic attacks/stroke, positive family history, cognitive decline (executive dysfunction), apathy or depression, subcortical white matter hyperintensities (mainly anterior temporal lobe, external capsule) in MRI brain

Spastic ataxia, optic neuropathy, bladder dysfunction (multisystem atrophy-cerebellar type /MSA-C mimicker)

Ataxia with parkinsonism, slow horizontal saccade (in SCA2), bulging eyes with upgaze palsy (in SCA3), autonomic dysfunction, cognitive decline and chorea (in SCA17), positive family history

Early onset parkinsonism, dystonia, with vertical supranuclear gaze palsy, history of seizure, cognitive decline

Frontotemporal dementia associated with amyotrophic lateral sclerosis (FTD-ALS phenotype), family history of early onset dementia/ALS, language dysfunction, hallucination, prominent parietal signs like apraxia, dyscalculia, visuospatial impairment
Radiological clues

Frontal and cerebellar atrophy, white matter T2 hyperintensities in parieto-occipital periventricular regions

T2 FLAIR hyperintensities in mesial temporal, dorsal midbrain, medial thalamus and hypothalamus

Mostly normal, may show brainstem, cerebellar and hippocampal atrophy, T2 FLAIR hyperintensities in hypothalamus and brainstem

T2 FLAIR hyperintensities in bilateral hippocampus and medial temporal lobes T2 FLAIR hyperintensities and mildly contrast enhancing lesions in midbrain, mesial temporal lobe, hypothalamus and corticospinal tracts

Symmetric fronto-temporal atrophy

Diffuse cerebral and cerebellar atrophy, increased iron accumulation can be seen in caudate and putamen in T2*/SWI MRI

Cerebellar atrophy, T2 hyperintensities in cerebellar white matter, dorsal thalamus and inferior olivary nucleus

Mostly normal, frontotemporal and midbrain atrophy can be seen

Normal or mild diffuse cortical and midbrain atrophy

T2 FLAIR hyperintensity and DWI restriction in caudate, putamen and thalamus, cortical ribboning in DWI MRI, cerebellar atrophy

Periventricular white matter T2 hyperintensities and characteristic hyperintensities of anterior temporal lobe and external capsule

Cerebellar atrophy

Cerebellar atrophy

Diffuse cortical atrophy, thinning of quadrigeminal plate, hippocampal sclerosis

Asymmetric fronto-temporal atrophy with temporo-parietal, parieto-occipital involvement 
TABLE 2 | Continued

\begin{tabular}{|c|c|c|c|}
\hline Clinical entity & Look-alikes (Mimics) & Clinical clues & Radiological clues \\
\hline & \multirow[t]{2}{*}{$\begin{array}{l}\text { Frontotemporal lobar degeneration } \\
\text { with FUS, C9orf72 and TANK-binding } \\
\text { kinase } 1 \text { (TBK1) gene mutation } \\
(80-84)\end{array}$} & $\begin{array}{l}\text { Frontotemporal dementia associated with amyotrophic } \\
\text { lateral sclerosis (FTD-ALS phenotype), family history of } \\
\text { dementia or ALS, history of hallucination, psychosis in } \\
\text { C9orf72 }\end{array}$ & \multirow[t]{2}{*}{$\begin{array}{l}\text { Frontotemporal atrophy, additional } \\
\text { caudate atrophy in FUS and cerebellar, } \\
\text { thalamic atrophy in C9orf72 }\end{array}$} \\
\hline & & $\begin{array}{l}\text { Primary progressive aphasia (CBS-PNFA) in TBK1 } \\
\text { mutation, }\end{array}$ & \\
\hline & $\begin{array}{l}\text { Familial and sporadic } \\
\text { Creutzfeldt-Jakob disease (CJD) } \\
(85-88)\end{array}$ & Rapid progression, cognitive decline, myoclonus, ataxia & $\begin{array}{l}\text { T2 FLAIR hyperintensity and DWI } \\
\text { restriction in caudate, putamen and } \\
\text { thalamus, cortical ribboning in DWI MRI }\end{array}$ \\
\hline & $\begin{array}{l}\text { Vascular insults like multi infarct state } \\
\text { (vascular CBS) (89-91) }\end{array}$ & $\begin{array}{l}\text { History of transient ischemic attacks or stroke, dementia, } \\
\text { history of dyslipidemia, ischemic heart disease, atrial } \\
\text { fibrillation, peripheral vascular disease }\end{array}$ & $\begin{array}{l}\text { MR evidence of multiple brain infarcts of } \\
\text { different stages, stenosis of internal carotid } \\
\text { arterial system in MR Angiography }\end{array}$ \\
\hline & $\begin{array}{l}\text { Antiphospholipid antibody syndrome } \\
\text { (APLA) with or without cerebral } \\
\text { infarction (92-94) }\end{array}$ & $\begin{array}{l}\text { History of repeated pregnancy loss, deep vein } \\
\text { thrombosis, chorea }\end{array}$ & $\begin{array}{l}\text { Multiple T2 hyperintensities in subcortical } \\
\text { white matter }\end{array}$ \\
\hline & $\begin{array}{l}\text { Presenilin } 1 \text { (PSEN1) mutation (95) } \\
\text { (gene responsible for early onset } \\
\text { Alzheimer's disease/EOAD) }\end{array}$ & $\begin{array}{l}\text { Family history of dementia, earlier age of onset than } \\
\text { classic CBS, seizure, cognitive impairment }\end{array}$ & $\begin{array}{l}\text { Diffuse cortical atrophy including } \\
\text { temporo-parietal lobe, subcortical and } \\
\text { periventricular white matter T2 } \\
\text { hyperintensities }\end{array}$ \\
\hline & $\begin{array}{l}\text { Amyloid precursor protein (APP) gene } \\
\text { mutation }(96,97) \text { (gene responsible } \\
\text { for early onset Alzheimer's } \\
\text { disease/EOAD) }\end{array}$ & $\begin{array}{l}\text { Family history of dementia and/or parkinsonism, earlier } \\
\text { age of onset than classic CBS, prominent cognitive } \\
\text { impairment, with or without seizure }\end{array}$ & Medial temporal/Hippocampal atrophy \\
\hline & $\begin{array}{l}\text { Cerebrotendinous xanthomatosis } \\
(\text { CTX) }(98,99) \text { (mutation in CYP27A1) }\end{array}$ & $\begin{array}{l}\text { Usual age of onset early than CBS, ataxia, tendon } \\
\text { xanthoma, early cataract, cognitive decline, spasticity }\end{array}$ & $\begin{array}{l}\text { Dentate and peri-dentate cerebellar white } \\
\text { matter T2 hyperintensities }\end{array}$ \\
\hline & $\begin{array}{l}\text { Fahr's disease (Primary familial brain } \\
\text { calcification/PFBC) (100) }\end{array}$ & $\begin{array}{l}\text { Usual age of onset early than CBS, history of seizure, } \\
\text { neuropsychiatric features including dementia, executive } \\
\text { dysfunction and psychosis, positive family history }\end{array}$ & $\begin{array}{l}\text { Evidence of bilateral brain calcification } \\
\text { (basal ganglia, dentate, centrum } \\
\text { semiovale) in CT or MRI }\end{array}$ \\
\hline & $\begin{array}{l}\text { Stiff limb syndrome (focal variant of } \\
\text { stiff person syndrome) }(101,102)\end{array}$ & $\begin{array}{l}\text { Fluctuating stiffness (more with activity), tonic spasms } \\
\text { provoked by tactile stimuli, anti GAD antibody positivity, } \\
\text { ataxia, history of autoimmune diseases like type } 1 \\
\text { diabetes, thyroiditis }\end{array}$ & $\begin{array}{l}\text { Mostly normal, T2 FLAIR hyperintensities } \\
\text { in medial temporal lobes can be seen }\end{array}$ \\
\hline & $\begin{array}{l}\text { Anti glycine receptor (anti-GlyR) } \\
\text { antibody mediated }(103,104)\end{array}$ & $\begin{array}{l}\text { Rapid progression, hyperekplexia (excessive startle), } \\
\text { progressive encephalomyelitis with rigidity and } \\
\text { myoclonus (PERM), trigeminal/facial disturbance, ataxia }\end{array}$ & $\begin{array}{l}\text { Mostly normal, subcortical and } \\
\text { periventricular white matter T2 } \\
\text { hyperintensities can be seen }\end{array}$ \\
\hline & $\begin{array}{l}\text { Diffuse Lewy body disease (DLB) } \\
(105,106)\end{array}$ & $\begin{array}{l}\text { Fluctuating cognition, visual hallucination, delusion, } \\
\text { neuroleptic sensitivity, autonomic dysfunction }\end{array}$ & $\begin{array}{l}\text { Diffuse cortical atrophy (with relatively } \\
\text { preserved medial temporal) in MRI and } \\
\text { occipital hypoperfusion with "cingulate } \\
\text { island sign" (preserved metabolism of the } \\
\text { posterior cingulate) on SPECT/PET }\end{array}$ \\
\hline & $\begin{array}{l}\text { Adult-onset leukoencephalopathy } \\
\text { with axonal spheroids and pigmented } \\
\text { glia (ALSP) due to CSF1R gene } \\
\text { mutation }(107,108)\end{array}$ & $\begin{array}{l}\text { Relative earlier onset than CBS, psychiatric symptoms } \\
\text { with personality change, progressive cognitive decline, } \\
\text { frontal executive dysfunction, pyramidal signs, history of } \\
\text { seizure, rapid disease course }\end{array}$ & $\begin{array}{l}\text { Dilation of the lateral ventricles, bilateral } \\
\text { white matter T2 FLAIR hyperintensities } \\
\text { with diffusion restriction, thinning of corpus } \\
\text { callosum, abnormal signal intensities in } \\
\text { corpus callosum and pyramidal } \\
\text { tract, calcifications in the white matter }\end{array}$ \\
\hline
\end{tabular}

visuospatial domains) that can mimic FTD or AD; (3) Motor (parkinsonism, ataxia, dysarthria, spasticity). Chronic postconcussive syndrome (CPCS) comes as differential but its temporal relation with the acute concussive event and the presence of headache are the helpful differentiating features (139). Pathologically CTE differs from AD, though both are secondary tauopathy with mixed 3R- and 4R-tau deposition. Perivascular deposition of tau positive NFTs along the depth of cortical sulci is the pathological hallmark of CTE. TDP43 inclusions are more common in CTE, while AB amyloid deposition is more in AD (142). Additionally, tau filaments in CTE have a unique $B$-helix region with a hydrophobic cavity, containing cofactors necessary for tau aggregation and propagation (143).

\section{Alzheimer's Disease (AD)}

$\mathrm{AD}$ is the most common cause of dementia worldwide. Pathologically, extracellular A $B$ amyloid plaques and intracellular tau (mixed $3 \mathrm{R}$ and $4 \mathrm{R}$ ) positive neurofibrillary tangles are 
TABLE 3 | Clinical, radiological, and pathological clues for GGT, AGD, and PiD.

\begin{tabular}{|c|c|c|c|}
\hline Disease entity & Clinical features & Radiology & Pathology \\
\hline $\begin{array}{l}\text { GGT }(28,115,116) \\
\text { (4R-tauopathy) }\end{array}$ & $\begin{array}{l}\text { - Can clinically present with bvFTD } \\
\text { (Type 1), PSP/CBS with MND/PLS } \\
\text { spectrum (Type 2) and mixed (Type } \\
\text { 3), based on topographic location } \\
\text { of white matter deposits of tau } \\
\text { immunoreactive globular glial } \\
\text { inclusions (117) } \\
\text { - Atypical PSP with marked upper } \\
\text { motor neuron (UMN) signs } \\
\text { (PSP-PLS phenotype) can be a } \\
\text { clinical clue } \\
\text { - Other phenotypes: PPA-G with } \\
\text { chorea (118), PPA-S (119), Mill's } \\
\text { hemiplegic variant of MND (120) }\end{array}$ & $\begin{array}{l}\text { - Frontotemporal atrophy with T2 FLAIR hyperintensities } \\
\text { in white matter involving cortical-white matter } \\
\text { junctions, subcortical and periventricular areas, } \\
\text { anterior commissure, posterior horn of lateral } \\
\text { ventricles, cerebral peduncle, basis pontis (regions } \\
\text { corresponding to traversing corticospinal fibers) } \\
(28,120,121)\end{array}$ & $\begin{array}{l}\text { Tau-immunoreactive globular inclusions } \\
\text { in astrocytes (GAl) and oligodendrocytes } \\
\text { (GOI) }(117,122) \\
\text { - Type 1: frontotemporal involvement } \\
\text { - Type 2: motor cortex and/or corticospinal } \\
\text { tract involvement } \\
\text { - Type 3: frontotemporal, motor cortex } \\
\text { and/or corticospinal tract involvement }\end{array}$ \\
\hline $\begin{array}{l}\text { PiD (129, 130) } \\
\text { (3R-tauopathy) }\end{array}$ & $\begin{array}{l}\text { - bvFTD (most common } \\
\text { presentation), sometimes can } \\
\text { present as PPA-S }\end{array}$ & $\begin{array}{l}\text { - bvFTD: Frontal (predominantly medial frontal cortex } \\
\text { and also involving dorsolateral and orbitofrontal } \\
\text { regions) > temporal atrophy }(131) \\
\text { - PPA-S: mainly left anterior temporal lobe, with } \\
\text { involvement of inferior temporal gyrus, fusiform gyrus, } \\
\text { anterior hippocampal region }(113,131)\end{array}$ & Pick bodies, Pick cells, ramified astrocytes \\
\hline
\end{tabular}

seen (144). Apart from classic amnestic presentation, nonamnestic phenotypes of $\mathrm{AD}$ are increasingly being recognized like, language variant (e.g., logopenic aphasia with word finding difficulty), visuospatial variant (posterior cortical atrophy/PCA with impaired spatial cognition), behavioral variant (executive dysfunction with impaired reasoning, problem solving), and mixed cognitive-motor presentation (atypical parkinsonism) (145, 146). In the latest National Institute on Aging and Alzheimer's Association (NIA-AA) Research
Framework criteria (2018), AD has been re-defined based on the underlying pathology (amyloid pathology/A, tau pathology/T and neurodegeneration/ $\mathrm{N}$ ) that can be documented in vivo by biomarkers or by post-mortem examination (147). From a movement disorder perspective, many studies have reported extrapyramidal signs including parkinsonism in $\mathrm{AD}$ with widely varied prevalence (20-100\%) (148). Parkinsonism in $\mathrm{AD}$ is mostly unresponsive to levodopa and the patients with AD-parkinsonism phenotype usually show relatively rapid 
TABLE 4 | Phenotypic presentations (chameleons) of IgLON5 disease.

Sleep disorders
Bulbar dysfunction
PSP phenotype
MSA phenotype
Acute or subacute
encephalopathy
Huntington's disease (HD)
phenotype
Orofacial dyskinesia

Motor neuron disease (MND) phenotype

Stiff-person syndrome spectrum (SPS) phenotype

Cerebellar ataxia phenotype

Cervical and truncal

dystonia
NREM and REM parasomnias (commonly vocalization, simple or finalistic limb movements, RBD), sleep apnea and stridor, excessive daytime somnolence

Dysphagia, dysarthria, laryngeal stridor, recurrent acute respiratory failure (mimicking ALS or myasthenia)

VSGP and gait instability (restriction in upgaze is more than downgaze in contrast to PSP)

Parasomnia, dysautonomia (urinary dysfunction, episodic profuse sweating), stridor, parkinsonism, ataxia

Cognitive impairment with chorea

Facial myokymia and orolingual myorhythmia (mimicking Whipple's disease)

Distal muscle atrophy, fasciculation

Peripheral nerve hyperexcitability with cramps, hyperekplexia, stiffness, myokymia, neuromyotonia

Postural and intention tremor, titubation, gait, and limb ataxia

the disease course in early onset familial $\mathrm{AD}$ and in $\mathrm{AD}$ with faster progression (156). Small amplitude postural jerky tremor (minipolymyoclonus) has also been reported in $\mathrm{AD}$ (157).

\section{Geographically Isolated Tauopathies-Sociocultural and Environmental Impact Guadeloupean Parkinsonism}

High frequency of atypical parkinsonism with PSP like presentation is seen in French-Caribbean islands of Guadeloupe and Martinique (158). Two phenotypes have been described: (1) Guadeloupean PSP-like syndrome (Gd-PSP) with levodoparesistant parkinsonism, early postural instability, and supranuclear gaze palsy (differs from classic PSP phenotype because of the high frequency of tremor, dysautonomia, and hallucination); (2) Guadeloupean Parkinsonism-dementia complex (Gd-PDC) with levodopa-resistant parkinsonism, subcortical dementia, and hallucination (9). Eating the fruits and infusions of the leaves of Annona muricata (soursop), containing Annonacin (toxic inhibitors of the mitochondrial respiratory chain complex I) has been proposed as a risk factor. Apart from supratentorial atrophy, 3rd ventricular dilatation (in both subgroups) and midbrain atrophy in Gd-PSP (like classic PSP), hypointense signals noted in T2 FLAIR, T2* sequences over substantia nigra, red nucleus, globus pallidus, and putamen in both subgroups (an important radiological clue) (9). Pathologically, they can mimic PSP or may have some atypical features like absence of tufted astrocytes and more tau positive neurons than true NFT (159).

progression, severe deficits on neuropsychological testing and high frequency of major depression and dysthymia (149). However, in these scenarios of cognitive-motor overlap, the clinicians must differentiate cortical "pseudo-parkinsonian" features like ideomotor apraxia, paratonic rigidity, and frontal/higher level gait disorders from true parkinsonian (nigrostriatal) features like bradykinesia, lead-pipe rigidity, and parkinsonian/middle-level gait disorders (148). Dementia with Lewy bodies/DLB (occurrence of dementia prior to or within a year of onset of motor symptoms, cognitive fluctuation, well-formed visual hallucination, neuroleptic sensitivity, and autonomic dysfunction), Parkinson's disease dementia/PDD (onset of dementia after 1 year of parkinsonian motor symptoms) and Creutzfeldt-Jakob disease/CJD (rapid progression, cerebellar ataxia, seizure, and chorea) can mimic AD-parkinsonism phenotype with dementia, rigidity, and myoclonus (149). Lastly, genes responsible for early onset $\mathrm{AD}$ (EOAD) like presenilin 1 (PSEN1) and amyloid precursor protein (APP) can give rise to atypical parkinsonism like corticobasal syndrome (CBS) $(95,96)$. Besides the CBS phenotype, dystonia in $\mathrm{AD}$ can also be drug-induced (e.g., rivastigmine, mirtazapine, neuroleptics) (150-152). Choline esterase inhibitors (ChEIs) can induce truncal dystonia in the form of Pisa syndrome (tonic lateral flexion of the trunk) in patients of $\mathrm{AD}$ (153-155). Apart from parkinsonism, cortical reflex myoclonus is common in advanced $\mathrm{AD}$ (in around 50\%). Myoclonus can appear early in

\section{Western Pacific Amyotrophic Lateral Sclerosis and Parkinsonism-Dementia Complex (ALS/PDC)}

Historically, epidemiologist Kurland and neurologist Mulder described the high incidence of atypical parkinsonism and familial ALS in Guam (southernmost of the Mariana islands) in native Chamorro tribe. Subsequently, Hirano et al. termed it as "Parkinsonism-dementia complex of Guam (PDC)" because of the common association of dementia (160). Three highincidence foci have been described so far in the literature: (1) Guam, USA ("Lytico-bodig" disease in Chamorro tribe), (2) PapuaNew Guinea, Indonesia (Auyu and Jakai tribe) (161), and (3) Hohara and Kozagawa regions of Kii Peninsula, Honshu Island, Japan ("Muro" disease) (10). Though the clinical description varied in literature, most common presentation described was rapidly progressive, familial, symmetric akineticrigid parkinsonism (PSP or "Bodig" phenotype) along with distal muscle atrophy (ALS or "Lytico" phenotype), hyperreflexia, vertical gaze palsy, and dementia (160). While overall the incidence of ALS/PDC has decreased, in Kii peninsula it is still being reported because of the use of traditional medicines (10). Ophthalmomyiasis-like pigmentary retinopathy ("criss-crossed tracks of depigmentation" of the retinal pigment epithelium) has been reported in these patients of Kii peninsula (162). MRI brain shows rapidly progressive frontotemporal atrophy mainly in PDC subtype (163). Typical "Hummingbird sign" (164) has been reported too. Pathologically, ALS/PDC can be called a 
"multiple proteinopathy" because apart from widespread 3R- and 4R-tau positive neuronal and glial inclusions, NFTs throughout the gray and white matter, including in the lower motor neurons in the spinal cord, TDP-43 deposits and accumulation of alpha synuclein deposition as Lewy bodies and Lewy neurites were also noted in the amygdala, substantia nigra and locus coeruleus (165). Several etiological hypotheses exist in the literature. Ingestion of toxic chemicals in the flour from seed of cycad plants containing toxic $\beta$-methylamino-l-alanine (1-BMAA) and cycasin has been proposed in "cycad hypothesis." Japanese folk medicine (Kampo) also contains Sotetsu seed (cycad) (10). Cyanobacteria (Blue-green algae) containing toxic BMAA reaches the cycad seeds via the roots and these native people cook bats who eat these cycad seeds (160). Interestingly, C9orf mutation has recently been reported in some of these people of Kii peninsula (166), but not in Guam (167).

\section{Nodding Syndrome (NS)}

Children in the East Africa, mostly the Acholi tribe in northern Uganda ("lucluc"), Wapogoro tribe of Tanzania ("kifafa cha kusinzia") and South Sudan suffer from a deleterious syndrome initially presenting as stereotypical head dropping movements (triggered by food, cold weather) that gradually leads to cognitive impairment, malnutrition, impaired growth, seizures, epileptic encephalopathy, and parkinsonism in late stage $(168,169)$. Often the affected children die by accidental drowning and burns. Clinically, NS overlaps with subSaharan Nakalanga syndrome (NLS) with pituitary dwarfism (169). Several etiological hypotheses exist in the literature, autoimmune reaction toleiomodin-1 epitope of Onchocerca volvulus (nematode causing river blindness) has been mostly mentioned. Recently, widespread tau-immunoreactive NFTs and pre-tangles have been noted, mostly in the gyral crests of the frontal and temporal cortex, brainstem, substantia nigra, and locus coeruleus (11). MRI shows varying degree of cortical atrophy mainly involving fronto-temporal regions (170). Presence of tau pathology in NS is a pathological factor for the disease or just an effect of repeated seizure, is still to be determined.

\section{Cluster of PSP in Northern France}

Caparros-Lefebvre et al. (171) have reported a cluster of older onset (mean age 74 years) PSP cases (53\% PSP-P, 33\% PSP-RS) from suburban towns centered on Wattrelos and Leers, northern France. Etiopathogenesis has been linked to the environmental toxic exposure from the industrial dumping of phosphate and chromate ores in the territory.

Being familiar with these disease phenotypes are needed because many a times patients migrate and a so-called "geographically isolated" tauopathy can present to a clinician practicing far away.

\section{Novel Tauopathies-Are They?}

Mulroy et al. (4) in their recent paper on "novel tauopathies," have highlighted how pathological tau deposition is interestingly being noted in some other movement disorders like ADCY5 related dyskinesia, Beta-propeller protein associated neurodegeneration
(BPAN), Benign hereditary chorea (BHC) Type 2, Huntington's disease (HD), Progressive ataxia, and palatal tremor (PAPT) and Spinocerebellar ataxia (SCA 11, 31). These are mostly isolated case reports and whether there is any pathological significance of tau in these disorders or tau is just an innocent bystander, is largely unknown. Presence of tau may be because of co-existing other known tauopathy, as a part of "mixed proteinopathy" or be just because of old age. Similarly, tau pathology is also seen in post encephalitic parkinsonism (172), Niemann-Pick type C disease (173) subacute sclerosing panencephalitis (SSPE) (174) and in prion disease like Gerstmann-Straussler-Scheinker disease (GSS) (175) although the clinico-pathological significance is still unknown.

\section{A PRACTICAL CLINICAL APPROACH TO TAUOPATHIES AND MOVEMENT DISORDERS}

Considering tauopathies from a movement disorder perspective, interlacing clinical phenotypes and pathological, genetic heterogeneity often make it difficult to diagnose them clinically. Some clinical pointers like VSGP, frontal disinhibited behavior, amyotrophy, prominent language involvement, chorea, and cerebellar ataxia can be helpful clues for the clinician on this regard (Figure 2).

\section{FAMILIAL FTD WITH PARKINSONISM-A PHENOTYPIC OVERLAP}

The overlap of familial frontotemporal dementia and parkinsonism needs special attention because it is one of the commonest presenting phenotypes baffling the movement disorder specialists. Frontotemporal dementia and parkinsonism linked to chromosome 17 (FTDP-17) has recently been described as "familial FTLD-tau" because of the similarity of neuropathological features and disease progression between patients of familial FTLD-tau with MAPT mutations and sporadic FTLD-tau subtypes (PiD, PSP, CBD, and GGT) (176). Parkinsonism associated with familial FTD and MAPT mutation varies from mild to the aggressive form in severity and can occur early or late in this spectrum (57). Chromosome 17 carries another gene named progranulin (PGRN), that is also linked with the spectrum of frontotemporal dementiaparkinsonism, but with TAR DNA binding protein 43 (TDP43) inclusions instead of tau. Apart from these two common genetic associations (MAPT and PGRN), parkinsonism in familial FTD can also be liked with chromosome 9 open reading frame 72 (C9orf72) gene where overlap with motor neuron disease (FTD-MND) is commonly seen $(177,178)$ (Table 6). Four other less common genetic links reported in familial FTD with parkinsonism cases are-chromatin modifying protein 2B (CHMP2B), transactive response DNA-binding protein (TARDBP), valosin-containing protein (VCP), and fused-in-sarcoma (FUS) genes (179-181). 


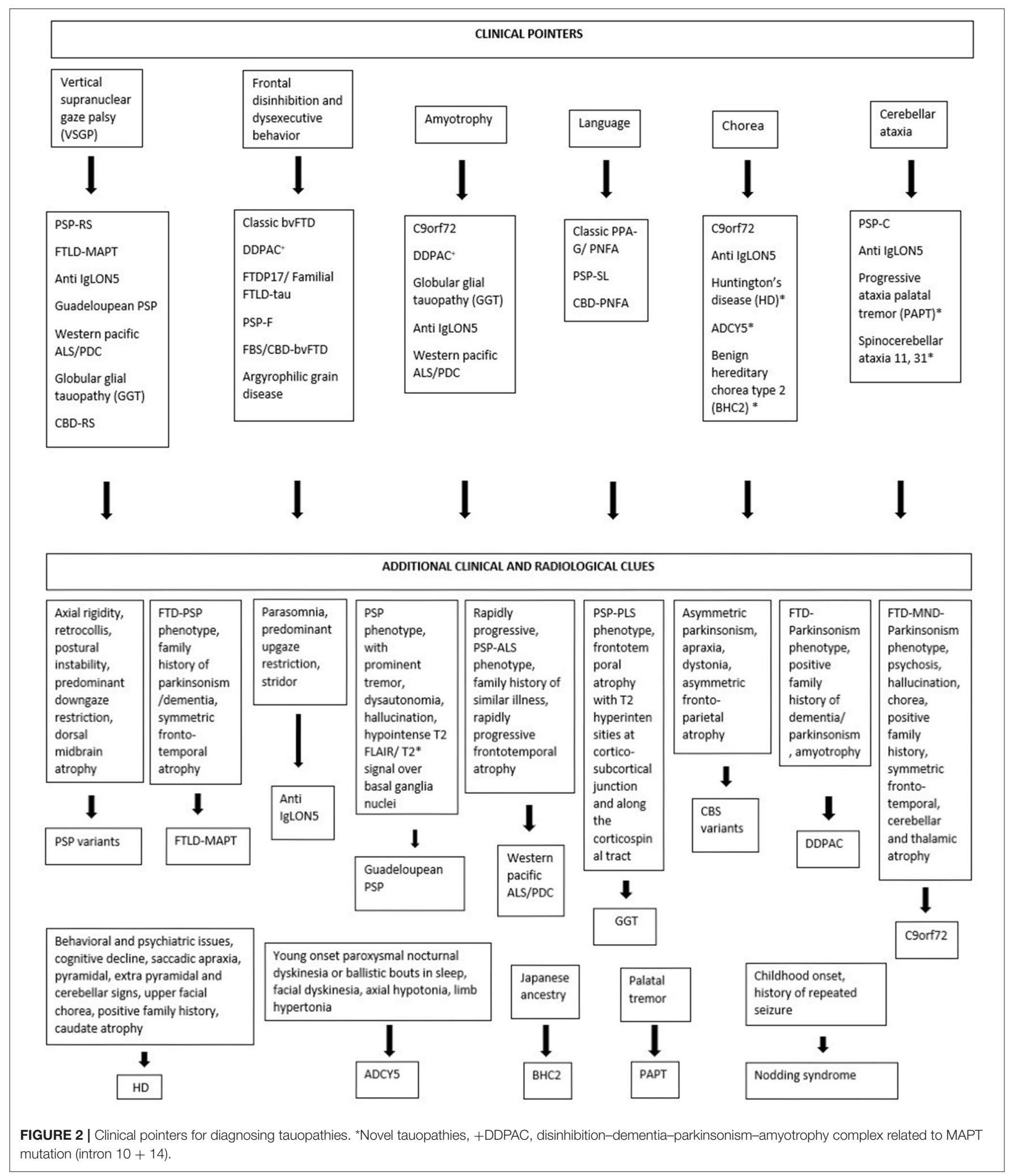

Phenotypically, MAPT and PGRN both can present with akinetic-rigid variant of parkinsonism. But MAPT commonly presents with PSP like phenotype with symmetric motor involvement while PGRN presents with corticobasal syndrome (CBS) like phenotype with asymmetric involvement and parietal lobe signs like apraxia, dyscalculia, visuoperceptual, 
TABLE 5 | Clinical and radiological clues for familial FTD with Parkinsonism.

\begin{tabular}{|c|c|c|c|}
\hline Clinical clues & Radiological clues & Targeted gene & $\begin{array}{l}\text { Suspected } \\
\text { pathology }\end{array}$ \\
\hline $\begin{array}{l}\text { Early onset (3rd or 4th decade), PSP } \\
\text { phenotype, vertical supranuclear gaze palsy }\end{array}$ & Symmetric fronto-temporal atrophy & MAPT & Tau \\
\hline $\begin{array}{l}\text { Late onset (5th or } 6 \text { th decade), CBS } \\
\text { phenotype, FTD-MND overlap, language } \\
\text { involvement, apraxia, dyscalculia, visuospatial } \\
\text { impairment, episodic memory involvement, } \\
\text { hallucination }\end{array}$ & $\begin{array}{l}\text { Asymmetric fronto-temporal atrophy, } \\
\text { more posterior involvement } \\
\text { (temporo-parietal, parieto-occipital), } \\
\text { significant white matter } \\
\text { hyperintensities }\end{array}$ & PGRN & TDP43 \\
\hline $\begin{array}{l}\text { FTD-MND overlap, early cognitive, and/or } \\
\text { behavioral symptoms, psychosis, hallucination, } \\
\text { chorea (Huntington's disease phenocopy), } \\
\text { positive family history of MND or FTD }\end{array}$ & $\begin{array}{l}\text { Symmetric fronto-temporal and } \\
\text { cerebellar atrophy }\end{array}$ & C9orf72 & TDP43, Ubiquitin \\
\hline
\end{tabular}

TABLE 6 | Clinical phenotypes associated with MAPT gene mutations.

\begin{tabular}{ll}
\hline Clinical Phenotype & MAPT gene mutation \\
\hline $\begin{array}{l}\text { Early prominent personality } \\
\text { change with } \\
\text { disinhibition-dementia- } \\
\text { parkinsonism-amyotrophy } \\
\text { complex (DDPAC) }\end{array}$ & intron $10+14(190,191)$ \\
Early onset aggressive & \\
parkinsonism & \\
& N279K, P301S, intron 10 + \\
CBS phenotype & $16, G 389 R$, intron 10 + 13 \\
& $(57)$ \\
Rest tremor (uncommon in & $\mathrm{N} 410 \mathrm{H}, \mathrm{P} 301 \mathrm{~S}(192,193)$ \\
FTD-parkinsonism) & $\mathrm{G} 389 \mathrm{R}, \mathrm{C} 291 \mathrm{R}(96)$ \\
\hline
\end{tabular}

and visuospatial dysfunction $(57,58,182)$. Penetrance is $100 \%$ in MAPT, while it is age dependent in PGRN and reaches about $90 \%$ at the age of 70 (58). So, if there is no family history, MAPT is unlikely but PGRN can still be a possibility. Progression of disease is relatively faster in PGRN (131) and hallucinations (183) are more common. Radiologically, symmetric fronto-temporal atrophy is seen in MAPT involving anteromedial temporal lobe and orbitofrontal region (184) while caudate atrophy (185) (also common in FUS) (186) can also be seen. However, PGRN commonly presents with asymmetric fronto-temporal atrophy and more prominent posterior atrophy involving temporoparietal, parieto-occipital regions $(58,182)$. White matter hyperintensities are more frequent in PGRN (187). Additional cerebellar and thalamic atrophy can be seen in C9orf72 along with symmetric frontotemporal atrophy $(188,189)$ (Table 5).

In addition to this, specific mutations in the MAPT gene can present with subtle phenotypic differences (57) (Table 6). On the other hand, Forrest et al. have noted pathological variability with specific mutations in MAPT like PSP pathology in S305S, CBD pathology in S305S, IVS10+16 and R406W, PiD pathology in K257T and GGT pathology in P301L, IVS10+16 mutation (176).

\section{CONCLUSION}

Tauopathy is a complex clinico-pathological hub encompassing multiple facets of movement disorders, dementia, and motor neuron disease. Topographic localization of tau accumulation shapes the clinical phenotype with varied combination of these domains. They can present with diverse overlapping phenotypes and their presentation can be mimicked by a lot of other diseases. Recognizing these "chameleons" and "mimics" are necessary from clinical and therapeutic standpoints. Emerging secondary tauopathies and geographically isolated tauopathies, many a time having relation with secondary environmental factors, are continuously invoking more and more research on the pathogenesis of tauopathy. Obviously, we can't stamp a disorder as "tauopathy" by mere presence of tau pathology in the brain. But is there a reliable clinical criterion for tagging a disorder as "tauopathy" ? MDS-PSP criteria has introduced the diagnostic category of "probable 4Rtauopathy" for ante mortem diagnosis of patients with PSP or CBD pathology (16). However, the spectrum of tauopathy is expanding far beyond these two pathological subtypes and tau deposition is being seen in different disease entities. Confirming the role of tau as a pathogenic factor for these disorders is the unmet need of the hour. The crosstalk between autoimmunity and neurodegeneration or neuroinflammation and tau aggregation also demands further research on this regard (196).

Traditionally, tauopathy has been depicted in the literature either as a pathological construct or from a cognitive perspective, while the evolving movement disorder domain of tauopathy is often neglected. Intertwining of the clinical, radiological, genetic, and pathological domains of movement disorder makes the spectrum intriguing but creates diagnostic confusion. Subtle clinical and radiological clues are the keys here to navigate through this conundrum. They are not only helpful for targeted genetic testing and predicting the pathology before autopsy, but also can open the door for utilizing newer biomarkers like ligand gated imaging or CSF biochemistry more efficiently and encourage further research on protein based therapeutic strategies. 


\section{AUTHOR CONTRIBUTIONS}

JG: organization and execution of the research project and writing of the first draft of the manuscript. MJ: conception of the research project and review and critique of the manuscript. Both authors contributed to the article and approved the submitted version.

\section{REFERENCES}

1. Warren JD, Rohrer JD, Schott JM, Fox NC, Hardy J, Rossor MN. Molecular nexopathies: a new paradigm of neurodegenerative disease. Trends Neurosci. (2013) 36:561-9. doi: 10.1016/j.tins.2013.06.007

2. Sanders DW, Kaufman SK, DeVos SL, Sharma AM, Mirbaha H, Li A, et al. Distinct tau prion strains propagate in cells and mice and define different tauopathies. Neuron. (2014) 82:1271-88. doi: 10.1016/j.neuron.2014.04.047

3. Landa J, Gaig C, Planagumà J, Saiz A, Antonell A, Sanchez-Valle $\mathrm{R}$, et al. Effects of IgLON5 antibodies on neuronal cytoskeleton: a link between autoimmunity and neurodegeneration. Ann Neurol. (2020). doi: 10.1002/ana.25857. [Epub ahead of print].

4. Mulroy E, Jaunmuktane Z, Balint B, Erro R, Latorre A, Bhatia KP. Some new and unexpected tauopathies in movement disorders. Mov Disord Clin Pract. (2020) 7:616-26. doi: 10.1002/mdc3.12995

5. Murley AG, Coyle-Gilchrist I, Rouse MA, Jones PS, Li W, Wiggins $\mathrm{J}$, et al. Redefining the multidimensional clinical phenotypes of frontotemporal lobar degeneration syndromes. Brain. (2020) 143:1555-71. doi: 10.1093/brain/awaa097

6. Ling $H$. Untangling the tauopathies: Current concepts of tau pathology and neurodegeneration. Park Relat Disord. (2018) 46:S34-S8. doi: 10.1016/j.parkreldis.2017.07.031

7. Caffrey TM, Wade-Martins R. Functional MAPT haplotypes: bridging the gap between genotype and neuropathology. Neurobiol Dis. (2007) 27:1-0. doi: 10.1016/j.nbd.2007.04.006

8. Rösler TW, Tayaranian Marvian A, Brendel M, Nykänen NP, Höllerhage M, Schwarz SC, et al. Four-repeat tauopathies. Prog Neurobiol. (2019) 180:101644. doi: 10.1016/j.pneurobio.2019.101644

9. Lannuzel A, Höglinger GU, Verhaeghe S, Gire L, Belson S, EscobarKhondiker M, et al. Atypical parkinsonism in Guadeloupe: a common risk factor for two closely related phenotypes? Brain. (2007) 130:816-27. doi: 10.1093/brain/awl347

10. Spencer PS, Palmer VS, Kihira T, Yoshida S, Reis J, Yabushita M, et al. Kampo medicine and Muro disease (Amyotrophic Lateral Sclerosis and Parkinsonism-Dementia Complex). eNeurologicalSci. (2020) 18:100230. doi: 10.1016/j.ensci.2020.100230

11. Pollanen MS, Onzivua S, Robertson J, McKeever PM, Olawa F, Kitara DL, et al. Nodding syndrome in Uganda is a tauopathy. Acta Neuropathol. (2018) 136:691-7. doi: 10.1007/s00401-018-1909-9

12. Höglinger GU, Respondek G, Kovacs GG. New classification of tauopathies. Rev Neurol (Paris). (2018) 174:664-8. doi: 10.1016/j.neurol.2018.07.001

13. Armstrong MJ. Progressive supranuclear palsy: an update. Curr Neurol Neurosci Rep. (2018) 18:1-9. doi: 10.1007/s11910-018-0819-5

14. Picillo M, Erro R, Cuoco S, Tepedino MF, Manara R, Pellecchia MT, et al. MDS PSP criteria in real-life clinical setting: motor and cognitive characterization of subtypes. Mov Disord. (2018) 33:1361-5. doi: $10.1002 / \mathrm{mds} .27408$

15. Iankova V, Respondek G, Saranza G, Painous C, Cámara A, Compta $\mathrm{Y}$, et al. Video-tutorial for the Movement Disorder Society criteria for progressive supranuclear palsy. Parkinsonism Relat Disord. (2020). doi: 10.1016/j.parkreldis.2020.06.030. [Epub ahead of print].

16. Höglinger GU, Respondek G, Stamelou M, Kurz C, Josephs KA, Lang AE, et al. Clinical diagnosis of progressive supranuclear palsy: the movement disorder society criteria. Mov Disord. (2017) 32:853-64.

\section{FUNDING}

No authors have received any funding from any institution, including personal relationships, interests, grants, employment, affiliations, patents, inventions, honoraria, consultancies, royalties, stock options/ownership, or expert testimony for the last 12 months.

17. Jalal MJ, Menon M. "Humming bird sign", "Mickey Mouse sign", and "morning glory sign" in progressive supranuclear palsy. Menoufia Med J. (2017) 30:325. doi: 10.4103/mmj.mmj_204_16

18. Massey LA, Jager HR, Paviour DC, O'Sullivan SS, Ling H, Williams $\mathrm{DR}$, et al. The midbrain to pons ratio: a simple and specific MRI sign of progressive supranuclear palsy. Neurology. (2013) 80:1856-61. doi: 10.1212/WNL.0b013e318292a2d2

19. Morelli M, Arabia G, Novellino F, Salsone M, Giofre L, Condino F, et al. MRI measurements predict PSP in unclassifiable parkinsonisms: a cohort study. Neurology. (2011) 77:1042-7. doi: 10.1212/WNL.0b013e31822e55d0

20. Quattrone A, Morelli M, Nigro S, Quattrone A, Vescio B, Arabia G, et al. A new MR imaging index for differentiation of progressive supranuclear palsyparkinsonism from Parkinson's disease. Park Relat Disord. (2018) 54:3-8. doi: 10.1016/j.parkreldis.2018.07.016

21. Boxer AL, Yu J-T, Golbe LI, Litvan I, Lang AE, Höglinger GU. Advances in progressive supranuclear palsy: new diagnostic criteria, biomarkers, and therapeutic approaches. Lancet Neurol. (2017) 16:552-63. doi: 10.1016/S1474-4422(17)30157-6

22. Jecmenica Lukic M, Kurz C, Respondek G, Grau-Rivera O, Compta Y, Gelpi E, et al. Copathology in progressive supranuclear palsy: does it matter? Mov Disord. (2020) 35:984-93. doi: 10.1002/mds.28011

23. Coughlin DG, Litvan I. Progressive supranuclear palsy: advances in diagnosis and management. Parkinsonism Relat Disord. (2020) 73:105-16. doi: 10.1016/j.parkreldis.2020.04.014

24. Kovacs GG, Lukic MJ, Irwin DJ, Arzberger T, Respondek G, Lee EB, et al. Distribution patterns of tau pathology in progressive supranuclear palsy. Acta Neuropathol. (2020) 140:99-119. doi: 10.1007/s00401-020-02158-2

25. Ling H. Clinical Approach to Progressive Supranuclear Palsy. J Mov Disord. (2016) 9:3-13. doi: 10.14802/jmd.15060

26. Ling H, Massey LA, Lees AJ, Brown P, Day BL. Hypokinesia without decrement distinguishes progressive supranuclear palsy from Parkinson's disease. Brain. (2012) 135:1141-53. doi: 10.1093/brain/aws038

27. Maetzler W, Rattay TW, Hobert MA, Synofzik M, Bader A, Berg D, et al. Freezing of Swallowing. Mov Disord Clin Pract. (2016) 3:490-3. doi: $10.1002 / \mathrm{mdc} 3.12314$

28. Liu AJ, Chang JE, Naasan G, Boxer AL, Miller BL, Spina S. Progressive supranuclear palsy and primary lateral sclerosis secondary to globular glial tauopathy: a case report and a practical theoretical framework for the clinical prediction of this rare pathological entity. Neurocase. (2020) 26:91-7. doi: 10.1080/13554794.2020.1732427

29. Ando S, Kanazawa M, Onodera O. Progressive supranuclear palsy with predominant cerebellar ataxia. J Mov Disord. (2020) 13:20-6. doi: 10.14802/jmd.19061

30. Armstrong MJ, Litvan I, Lang AE, Bak TH, Bhatia KP, Borroni B, et al. Criteria for the diagnosis of corticobasal degeneration. Neurology. (2013) 80:496-503. doi: 10.1212/WNL.0b013e31827fofd1

31. Day GS, Sung Lim T, Hassenstab J, Goate AM, Grant EA, Roe $\mathrm{CM}$, et al. Differentiating cognitive impairment due to corticobasal degeneration and Alzheimer disease. Neurology. (2017) 88:1273-81. doi: 10.1212/WNL.0000000000003770

32. Abbate C, Trimarchi PD, Manzoni L, Quarenghi AM, Salvi G Pietro, Inglese $\mathrm{S}$, et al. A posterior variant of corticobasal syndrome: evidence from a longitudinal study of cognitive and functional status in a single case. Cogent Psychol. (2018) 5. doi: 10.1080/23311908.2018.1452868 
33. Lang AE. Cortical basal ganglionic degeneration presenting with "progressive loss of speech output and orofacial dyspraxia." J Neurol Neurosurg Psychiatry. (1992) 55:1101. doi: 10.1136/jnnp.55.11.1101

34. Thümler BH, Urban PP, Davids E, Siessmeier M, Schreckenberger T, Benz P, et al. Dysarthria and pathological laughter/crying as presenting symptoms of corticobasal- ganglionic degeneration syndrome. J Neurol. (2003) 250:11078. doi: $10.1007 / \mathrm{s} 00415-003-0075-7$

35. Kimura N, Kumamoto T, Hanaoka T, Hazama Y, Nakamura K, Arakawa R. Corticobasal degeneration presenting with progressive conduction aphasia. $J$ Neurol Sci. (2008) 269:163-8. doi: 10.1016/j.jns.2007.12.017

36. Rossor MN, Tyrrell PJ, Warrington EK, Thompson PD, Marsden CD, Lantos P. Progressive frontal gait disturbance with atypical Alzheimer's disease and corticobasal degeneration. J Neurol Neurosurg Psychiatry. (1999) 67:345-52. doi: 10.1136/jnnp.67.3.345

37. Sakae N, Santos OA, Pedraza O, Litvan I, Murray ME, Duara R, et al. Clinical and pathologic features of cognitive-predominant corticobasal degeneration. Neurology. (2020) 95:e35-e45. doi: 10.1212/WNL.0000000000009734

38. Constantinides VC, Paraskevas GP, Paraskevas PG, Stefanis L, Kapaki E. Clinical Parkinsonism \& Related Disorders Corticobasal degeneration and corticobasal syndrome : a review. Clin Park Relat Disord. (2019) 1:66-71. doi: 10.1016/j.prdoa.2019.08.005

39. Whitwell JL, Jack CR, Boeve BF, Parisi JE, Ahlskog JE, Drubach DA, et al. Imaging correlates of pathology in corticobasal syndrome. Neurology. (2010) 75:1879-87. doi: 10.1212/WNL.0b013e3181feb2e8

40. Ling H, O'Sullivan SS, Holton JL, Revesz T, Massey LA, Williams DR, et al. Does corticobasal degeneration exist? A clinicopathological re-evaluation. Brain. (2010) 133:2045-57. doi: 10.1093/brain/awq123

41. Höglinger GU. Is it useful to classify progressive supranuclear palsy and corticobasal degeneration as different disorders? No. Mov Disord Clin Pract. (2018) 5:141-4. doi: 10.1002/mdc3.12582

42. Ling $\mathrm{H}$, Macerollo A. Is it useful to classify PSP and CBD as different disorders? Yes. Mov Disord Clin Pract. (2018) 5:145-8. doi: $10.1002 / \mathrm{mdc} 3.12581$

43. Respondek G, Grimm MJ, Piot I, Arzberger T, Compta Y, Englund E, et al. Validation of the movement disorder society criteria for the diagnosis of 4-repeat tauopathies. Mov Disord. (2020) 35:171-6. doi: 10.1002/mds. 27872

44. Lang AE. Comment on "Is it Useful to Classify PSP and CBD as Different Disorders?" Mov Disord Clin Pract. (2018) 5:564-5. doi: 10.1002/mdc3.12676

45. Giagkou N, Bhatia KP, Höglinger GU, Stamelou M. Genetic mimics of the non-genetic atypical parkinsonian disorders - the 'atypical' atypical. Int Rev Neurobiol. (2019) 149:327-51. doi: 10.1016/bs.irn.2019. 10.008

46. Stamelou M, Quinn NP, Bhatia KP. "Atypical” atypical parkinsonism: new genetic conditions presenting with features of progressive supranuclear palsy, corticobasal degeneration, or multiple system atrophy-a diagnostic guide. Mov Disord. (2013) 28:1184-99. doi: 10.1002/mds.25509

47. Eggink H, Brandsma R, van der Hoeven JH, Lange F, de Koning TJ, Tijssen MAJ. Teaching video neuro images : the "round the houses" sign as a clinical clue for Niemann-Pick disease type C. Neurology. (2016) 86:e202. doi: 10.1212/WNL.0000000000002660

48. Kresojević N, Mandić-Stojmenović G, Dobričić V, Petrović I, Brajković L, Stefanova E, et al. Very late-onset niemann pick type c disease: example of progressive supranuclear palsy look-alike disorder. Mov Disord Clin Pract. (2020) 7:211-4. doi: 10.1002/mdc3.12892

49. Dalmau J. Clinical analysis of anti-Ma2-associated encephalitis. Brain. (2004) 127:1831-44. doi: 10.1093/brain/awh203

50. Gövert F, Leypoldt F, Junker R, Wandinger K-P, Deuschl G, Bhatia KP, et al. Antibody-related movement disorders - a comprehensive review of phenotype-autoantibody correlations and a guide to testing. Neurol Res Pract. (2020) 2:6. doi: 10.1186/s42466-020-0053-x

51. Gaig C, Graus F, Compta Y, Högl B, Bataller L, Brüggemann N, et al. Clinical manifestations of the anti-IgLON5 disease. Neurology. (2017) 88:1736-43. doi: 10.1212/WNL.0000000000003887

52. Chen $\mathrm{H}, \mathrm{Wu} \mathrm{J}$, Irani $\mathrm{SR}$. Distinctive magnetic resonance imaging findings in IgLON5 antibody disease. JAMA Neurol. (2020) 77:125. doi: 10.1001/jamaneurol.2019.3638
53. Merchán-del Hierro X, Rojas G, Aldinio V, Bres-Bullrich M, Da-Prat G, Ebner R, et al. Moaning phenomenon and rapidly progressive dementia in anti LGI-1 associated progressive supranuclear palsy syndrome. Tremor Other Hyperkinet Mov. (2020) 10:8. doi: 10.5334/tohm.65

54. van Sonderen A, Thijs RD, Coenders EC, Jiskoot LC, Sanchez E, de Bruijn MAAM, et al. Anti-LGI1 encephalitis. Neurology. (2016) 87:1449-456. doi: 10.1212/WNL.0000000000003173

55. Averbuch-Heller L, Paulson GW, Daroff RB, Leigh RJ. Whipple's disease mimicking progressive supranuclear palsy: the diagnostic value of eye movement recording. J Neurol Neurosurg Psychiatry. (1999) 66:532-5. doi: 10.1136/jnnp.66.4.532

56. Black DF, Aksamit AJ, Morris JM. MR imaging of central nervous system whipple disease: a 15-year review. Am J Neuroradiol. (2010) 31:1493-7. doi: 10.3174/ajnr.A2089

57. Baizabal-Carvallo JF, Jankovic J. Parkinsonism, movement disorders and genetics in frontotemporal dementia. Nat Rev Neurol. (2016) 12:175-85. doi: 10.1038/nrneurol.2016.14

58. Espay AJ, Litvan I. Parkinsonism and frontotemporal dementia: the clinical overlap. J Mol Neurosci. (2011) 45:343-9. doi: 10.1007/s12031-011-9632-1

59. Williams DR, Hadeed A, Najim AS, Wreikat A, Lees AJ. Kufor Rakeb Disease: autosomal recessive, levodopa- responsive parkinsonism with pyramidal degeneration, supranuclear gaze palsy, and dementia. (2005) 20:1264-71. doi: $10.1002 / \mathrm{mds} .20511$

60. Yang $\mathrm{X}, \mathrm{Xu} \mathrm{Y}$. Mutations in the ATP13A2 gene and Parkinsonism: a preliminary review. Biomed Res Int. (2014) 2014:1-9. doi: 10.1155/2014/371256

61. Henao AI, Pira S, Herrera DA, Vargas SA, Montoya J, Castillo M. Characteristic brain MRI findings in ataxia-neuropathy spectrum related to POLG mutation. Neuroradiol J. (2016) 29:46-8. doi: 10.1177/1971400915621324

62. Newsway V, Fish M, Rohrer JD, Majounie E, Williams N, Hack M, et al. Europe PMC Funders Group Perry syndrome due to the DCTN1 G71R mutation - a distinctive L-DOPA responsive disorder with behavioural syndrome, vertical gaze palsy and respiratory failure. (2015) 25:767-70. doi: $10.1002 / \mathrm{mds} .22950$

63. Erro R, Stamelou M, Bhatia KP. editors. (Familial) PSP Look-Alike: Perry Syndrome. In: Case Studies in Movement Disorders. Cambridge: Cambridge University Press. (2017). p. 24-5.

64. Konno T, Ross OA, Teive HAG, Slawek J, Dickson DW, Wszolek ZK. DCTN1-related neurodegeneration: perry syndrome and beyond. Parkinsonism Relat Disord. (2017) 41:14-24. doi: 10.1016/j.parkreldis.2017.06.004

65. Picillo M, Petrucci S, Valente EM, Pappatà S, Squame F, Ginevrino M, et al. Progressive supranuclear palsy-like phenotype in a GBA E326K mutation carrier. Mov Disord Clin Pract. (2017) 4:444-6. doi: 10.1002/mdc3.12406

66. Bertoni JM, Label LS, Sackelleres JC, Hicks SP. Supranuclear gaze palsy in familial Creutzfeldt-Jakob disease. Arch Neurol. (1983) 40:618-22. doi: 10.1001/archneur.1983.04050090054008

67. Fulbright RK, Hoffmann C, Lee H, Pozamantir A, Chapman J, Prohovnik I. MR imaging of familial creutzfeldt-jakob disease: a blinded and controlled study. Am J Neuroradiol. (2008) 29:1638-43. doi: 10.3174/ajnr.A1217

68. Ufkes NA, Woodard C, Dale ML. A case of Gerstmann-Straussler-Scheinker (GSS) disease with supranuclear gaze palsy. J Clin Mov Disord. (2019) 6:7. doi: 10.1186/s40734-019-0082-1

69. Ribosa-Nogué R, Pagonabarraga J, Gomez-Anson B, Granell-Moreno E, Sánchez-Valle R, Kulisevsky J. Gerstmann-Sträussler-Scheinker disease presenting with atypical parkinsonism, but typical magnetic resonance imaging findings of prion disease. Mov Disord Clin Pract. (2016) 3:93-95. doi: $10.1002 / \mathrm{mdc} 3.12228$

70. Erro R, Lees AJ, Moccia M, Picillo M, Penco S, Mosca L, et al. Progressive Parkinsonism, Balance Difficulties, and Supranuclear Gaze Palsy. JAMA Neurol. (2014) 71:104. doi: 10.1001/jamaneurol.2013.5149

71. Stojanov D, Vojinovic S, Aracki-Trenkic A, Tasic A, BenedetoStojanov D, Ljubisavljevic S, et al. Imaging characteristics of cerebral autosomal dominant arteriopathy with subcortical infarcts and leucoencephalopathy (CADASIL). Bosn J Basic Med Sci. (2015) 15:1-8. doi: 10.17305/bjbms.2015.247 
72. Pfeffer G, Gorman GS, Griffin H, Kurzawa-Akanbi M, Blakely EL, Wilson I, et al. Mutations in the SPG7 gene cause chronic progressive external ophthalmoplegia through disordered mitochondrial DNA maintenance. Brain. (2014) 137:1323-36. doi: 10.1093/brain/awu060

73. De la Casa-Fages B, Fernández-Eulate G, Gamez J, Barahona-Hernando R, Morís G, García-Barcina M, et al. Parkinsonism and spastic paraplegia type 7: expanding the spectrum of mitochondrial Parkinsonism. Mov Disord. (2019) 34:1547-61. doi: 10.1002/mds. 27812

74. Da Graça FF, De Rezende TJR, Vasconcellos LFR, Pedroso JL, Barsottini OGP, França MC. Neuroimaging in hereditary spastic paraplegias: current use and future perspectives. Front Neurol. (2019) 10:1117. doi: 10.3389/fneur.2018.01117

75. Gwinn-Hardy K, Chen JY, Liu H-C, Liu TY, Boss M, Seltzer W, et al. Spinocerebellar ataxia type 2 with parkinsonism in ethnic Chinese. Neurology. (2000) 55:800-5. doi: 10.1212/WNL.55.6.800

76. Nascimento FA, Marques Garcia BC, Teive HAG. Teaching Video NeuroImages: upward gaze palsy is a sign of spinocerebellar ataxia type 3 . Neurology. (2018) 91:e494. doi: 10.1212/WNL.0000000000005913

77. Lin I-S, Wu R-M, Lee-Chen G-J, Shan D-E, Gwinn-Hardy K. The SCA17 phenotype can include features of MSA-C, PSP and cognitive impairment. Parkinsonism Relat Disord. (2007) 13:246-9. doi: 10.1016/j.parkreldis.2006.04.009

78. Park H, Kim H-J, Jeon BS. Parkinsonism in spinocerebellar ataxia. Biomed Res Int. (2015) 1-11. doi: 10.1155/2015/125273

79. Quadri M, Fang M, Picillo M, Olgiati S, Breedveld GJ, Graafland J, et al. Mutation in the SYNJ1 gene associated with autosomal recessive, early-onset parkinsonism. Hum Mutat. (2013) 34:1208-15. doi: 10.1002/humu.22373

80. Huey ED, Ferrari R, Moreno JH, Jensen C, Morris CM, Potocnik F, et al. FUS and TDP43 genetic variability in FTD and CBS. Neurobiol Aging. (2012) 33:1016.e9-e17. doi: 10.1016/j.neurobiolaging.2011.08.004

81. Anor CJ, Xi Z, Zhang M, Moreno D, Sato C, Rogaeva E, et al. Mutation analysis of C9orf72 in patients with corticobasal syndrome. Neurobiol Aging. (2015) 36:2905.e1-e5. doi: 10.1016/j.neurobiolaging.2015.06.008

82. Souza PVS de, Pinto WBV de R, Oliveira ASB. C9orf72-related disorders: expanding the clinical and genetic spectrum of neurodegenerative diseases. Arq Neuropsiquiatr. (2015) 73:246-256. doi: 10.1590/0004-282X20140229

83. Lamb R, Rohrer JD, Real R, Lubbe SJ, Waite AJ, Blake DJ, et al. A novel TBK1 mutation in a family with diverse frontotemporal dementia spectrum disorders. Cold Spring Harb Mol Case Stud. (2019) 5:1-10. doi: $10.1101 /$ mcs.a003913

84. Caroppo P, Camuzat A, De Septenville A, Couratier P, Lacomblez L, Auriacombe S, et al. Semantic and nonfluent aphasic variants, secondarily associated with amyotrophic lateral sclerosis, are predominant frontotemporal lobar degeneration phenotypes in TBK1 carriers. Alzheimers Dement. (2015) 1:481-6. doi: 10.1016/j.dadm.2015.10.002

85. Herrero Valverde A, Costa S, Timoteo Â, Ginestal R, Pimentel J. Rapidly progressive corticobasal degeneration syndrome. Case Rep Neurol. (2011) 3:185-90. doi: 10.1159/000329820

86. Zhang Y, Minoshima S, Vesselle H, Lewis DH. A case of CreutzfeldtJakob disease mimicking corticobasal degeneration. Clin Nucl Med. (2012) 37:e173-e5. doi: 10.1097/RLU.0b013e31824c5f0e

87. Necpál J, Stelzer M, Koščová S, Patarák M. A corticobasal syndrome variant of familial Creutzfeldt-Jakob disease with stroke-like onset. Case Rep Neurol Med. (2016) 2016:1-3. doi: 10.1155/2016/4167391

88. Lee W, Simpson M, Ling H, McLean C, Collins S, Williams DR. Characterising the uncommon corticobasal syndrome presentation of sporadic Creutzfeldt-Jakob disease. Park Relat Disord. (2013) 19:81-5. doi: 10.1016/j.parkreldis.2012.07.010

89. Kim Y-D, Kim J-S, Lee E-S, Yang D-W, Lee K-S, Kim Y-I. Progressive "vascular" corticobasal syndrome due to bilateral ischemic hemispheric lesions. Intern Med. (2009) 48:1699-702. doi: 10.2169/internalmedicine.48.2415

90. Engelen M, Westhoff D, de Gans J, Nederkoorn PJ. A 64-year old man presenting with carotid artery occlusion and corticobasal syndrome: a case report. J Med Case Rep. (2011) 5:357. doi: 10.1186/1752-19475-357

91. Koga S, Roemer SF, Kasanuki K, Dickson DW. Parkinsonism and related disorders cerebrovascular pathology presenting as corticobasal syndrome: an autopsy case series of “vascular CBS.” Park Relat Disord. (2019) 68:79-84. doi: 10.1016/j.parkreldis.2019.09.001

92. Morris HR, Lees AJ. Primary antiphospholipid syndrome presenting as a corticobasal degeneration syndrome. Mov Disord. (1999) 14:530-2. doi: 10.1002/1531-8257(199905)14:3<530::AID-MDS1030>3.0.CO;2-8

93. Martino D, Chew N-K, Mir P, Edwards MJ, Quinn NP, Bhatia KP. Atypical movement disorders in antiphospholipid syndrome. Mov Disord. (2006) 21:944-9. doi: 10.1002/mds.20842

94. Lee D-W, Eum S-W, Moon CO, Ma H-I, Kim YJ. Corticobasal syndrome associated with antiphospholipid syndrome without cerebral infarction. Neurology. (2014) 82:730-1. doi: 10.1212/WNL.0000000000000152

95. Navarro E, De Andrés C, Guerrero C, Giménez-Roldán S. Corticobasal syndrome in a family with early-onset Alzheimer's disease linked to a presenilin-1 gene mutation. Mov Disord Clin Pract. (2015) 2:388-94. doi: $10.1002 / \mathrm{mdc} 3.12212$

96. Abate F, Dati G, Ginevrino M, Valente EM, Barone P, Picillo M. APP-related corticobasal syndrome: expanding the list of corticobasal degeneration look alikes. Mov Disord Clin Pract. (2020) 7:849-51. doi: 10.1002/mdc3.13037

97. Scahill RI, Ridgway GR, Bartlett JW, Barnes J, Ryan NS, Mead S, et al. Genetic influences on atrophy patterns in familial Alzheimer's disease: a comparison of APP and PSEN1 mutations. J Alzheimers Dis. (2013) 35:199212. doi: 10.3233/JAD-121255

98. Rubio-Agusti I, Kojovic M, Edwards MJ, Murphy E, Chandrashekar HS, Lachmann RH, et al. Atypical parkinsonism and cerebrotendinous xanthomatosis: report of a family with corticobasal syndrome and a literature review. Mov Disord. (2012) 27:1769-74. doi: 10.1002/mds.25229

99. Stelten BML, van de Warrenburg BPC, Wevers RA, Verrips A. Movement disorders in cerebrotendinous xanthomatosis. Park Relat Disord. (2019) 58:12-6. doi: 10.1016/j.parkreldis.2018.07.006

100. Warren JD, Mummery CJ, Al-Din AS, Brown P, Wood NW. Corticobasal degeneration syndrome with basal ganglia calcification: Fahr's disease as a corticobasal look-alike? Mov Disord. (2002) 17:563-7. doi: $10.1002 / \mathrm{mds} .10122$

101. Balint B, Mahant N, Meinck HM, Fung V. Stiff limb syndrome mimicking corticobasal syndrome. Mov Disord Clin Pract. (2014) 1:354-6. doi: $10.1002 / \mathrm{mdc} 3.12059$

102. Graus F, Saiz A, Dalmau J. GAD antibodies in neurological disorders - insights and challenges. Nat Rev Neurol. (2020) 16:353-65. doi: 10.1038/s41582-020-0359-x

103. Muñoz González A, Contreras Chicote A, Vales Montero M, Velázquez Pérez JM, Dela Casa B, Luque Buzo E, et al. Antiglycine receptor antibodies and rapidly progressive corticobasal syndrome [abstract]. Mov Disord. (2018) 33(Suppl 2).

104. Carvajal-González A, Leite MI, Waters P, Woodhall M, Coutinho E, Balint $\mathrm{B}$, et al. Glycine receptor antibodies in PERM and related syndromes: characteristics, clinical features and outcomes. Brain. (2014) 137:2178-92. doi: 10.1093/brain/awu142

105. Kasanuki K, Josephs KA, Ferman TJ, Murray ME, Koga S, Konno T, et al. Diffuse Lewy body disease manifesting as corticobasal syndrome a rare form of Lewy body disease. Neurology. (2018) 91:E268-E79. doi: 10.1212/WNL.0000000000005828

106. Mak E, Su L, Williams GB, O’Brien JT. Neuroimaging characteristics of dementia with Lewy bodies. Alzheimers Res Ther. (2014) 6:18. doi: $10.1186 /$ alzrt248

107. Konno T, Yoshida K, Mizuno T, Kawarai T, Tada M, Nozaki H, et al. Clinical and genetic characterization of adult-onset leukoencephalopathy with axonal spheroids and pigmented glia associated with CSF1R mutation. Eur J Neurol. (2017) 24:37-45. doi: 10.1111/ene.13125

108. Baba Y, Ghetti B, Baker MC, Uitti RJ, Hutton ML, Yamaguchi K, et al. Hereditary diffuse leukoencephalopathy with spheroids: clinical, pathologic and genetic studies of a new kindred. Acta Neuropathol. (2006) 111:300-11. doi: 10.1007/s00401-006-0046-z

109. Marshall CR, Hardy CJD, Volkmer A, Russell LL, Bond RL, Fletcher PD, et al. Primary progressive aphasia: a clinical approach. J Neurol. (2018) 265:1474-90. doi: 10.1007/s00415-018-8762-6

110. Ash S, Mcmillan C, Gunawardena D, Avants B, Morgan B, Khan A, et al. Brain \& Language Speech errors in progressive non-fluent aphasia. Brain Lang. (2010) 113:13-20. doi: 10.1016/j.bandl.2009.12.001 
111. Gorno-Tempini ML, Hillis AE, Weintraub S, Kertesz A, Mendez M, Cappa $\mathrm{SF}$, et al. Classification of primary progressive aphasia and its variants. Neurology. (2011) 76:1006-14. doi: 10.1212/WNL.0b013e31821103e6

112. Grossman M. The non-fluent / agrammatic variant of primary progressive aphasia. Lancet Neurol. (2012) 11:545-55. doi: 10.1016/S1474-4422(12)70099-6

113. Montembeault M, Brambati SM, Gorno-Tempini ML, Migliaccio R. Clinical, anatomical, and pathological features in the three variants of primary progressive aphasia: a review. Front Neurol. (2018) 9:692. doi: 10.3389/fneur.2018.00692

114. Tan RH, Guennewig B, Dobson-Stone C, Kwok JBJ, Kril JJ, Kiernan MC, et al. The underacknowledged PPA-ALS. Neurology. (2019) 92:e1354 LP-e66. doi: 10.1212/WNL.0000000000007146

115. Josephs KA, Katsuse O, Beccano-Kelly DA, Lin W-L, Uitti RJ, Fujino $\mathrm{Y}$, et al. Atypical progressive supranuclear palsy with corticospinal tract degeneration. J Neuropathol Exp Neurol. (2006) 65:396-405. doi: 10.1097/01.jnen.0000218446.38158.61

116. Fu Y-J, Nishihira Y, Kuroda S, Toyoshima Y, Ishihara T, Shinozaki M, et al. Sporadic four-repeat tauopathy with frontotemporal lobar degeneration, Parkinsonism, and motor neuron disease: a distinct clinicopathological and biochemical disease entity. Acta Neuropathol. (2010) 120:21-32. doi: 10.1007/s00401-010-0649-2

117. Ahmed Z, Bigio EH, Budka H, Dickson DW, Ferrer I, Ghetti B, et al. Globular glial tauopathies (GGT): consensus recommendations. Acta Neuropathol. (2013) 126:537-44. doi: 10.1007/s00401-013-1171-0

118. Kim E-J, Lee MJ, Lee J-H, Lee YM, Shin J-H, Shin M-J, et al. Globular glial tauopathy presenting as non-fluent/agrammatic variant primary progressive aphasia with chorea. Parkinsonism Relat Disord. (2017) 44:15961. doi: 10.1016/j.parkreldis.2017.09.006

119. Graff-Radford J, Josephs KA, Parisi JE, Dickson DW, Giannini C, Boeve BF. Globular glial Tauopathy presenting as semantic variant primary progressive aphasia. JAMA Neurol. (2016) 73:123. doi: 10.1001/jamaneurol.201 5.2711

120. Marsili L, Dickson DW, Espay AJ. Globular glial tauopathy may be mistaken for corticobasal syndrome-pointers for the clinician. Mov Disord Clin Pract. (2018) 5:439-41. doi: 10.1002/mdc3. 12634

121. Kovacs GG, Majtenyi K, Spina S, Murrell JR, Gelpi E, Hoftberger R, et al. White matter tauopathy with globular glial inclusions: a distinct sporadic frontotemporal lobar degeneration. J Neuropathol Exp Neurol. (2008) 67:963-75. doi: 10.1097/NEN.0b013e318187a80f

122. Kovacs GG. Astroglia and tau: new perspectives. Front Aging Neurosci. (2020) 12:96. doi: 10.3389/fnagi.2020.00096

123. Rodriguez RD, Grinberg LT. Argyrophilic grain disease: an underestimated tauopathy. Dement Neuropsychol. (2015) 9:2-8. doi: 10.1590/S1980-57642015DN91000002

124. Yokota O, Miki T, Ikeda C, Nagao S, Takenoshita S, Ishizu H, et al. Neuropathological comorbidity associated with argyrophilic grain disease. Neuropathology. (2018) 38:82-97. doi: 10.1111/neup.12429

125. Sengoku R, Kaneda D, Kameyama M, Tokumaru A, Ishii K, Kanemaru K, et al. An atutopsy case of argyrophilic grain disease, clinically presenting with Parkinson dementia [abstract]. Mov Disord. (2018) 33.

126. Jicha GA, Nelson PT. Hippocampal sclerosis, argyrophilic grain disease, and primary age-related tauopathy. Contin Lifelong Learn Neurol. (2019) 25:208-33. doi: 10.1212/CON.0000000000000697

127. Gil MJ, Serrano S, Manzano MS, Cuadrado ML, Góméz E, Rábano A. Argyrophilic grain disease presenting as behavioral frontotemporal dementia. Clin Neuropathol. (2019) 38:8-13. doi: 10.5414/NP301122

128. Wurm R, Klotz S, Rahimi J, Katzenschlager R, Lindeck-Pozza E, Regelsberger $\mathrm{G}$, et al. Argyrophilic grain disease in individuals younger than 75 years: clinical variability in an under-recognized limbic tauopathy. Eur J Neurol. (2020) 27:1856-66. doi: 10.1111/ene.14321

129. Rossor MN. Pick's disease: a clinical overview. Neurology. (2001) 56:S3-S5. doi: 10.1212/WNL.56.suppl_4.S3

130. Irwin DJ, Brettschneider J, McMillan CT, Cooper F, Olm C, Arnold $\mathrm{SE}$, et al. Deep clinical and neuropathological phenotyping of Pick disease. Ann Neurol. (2016) 79:272-87. doi: 10.1002/ana. 24559
131. Whitwell JL, Josephs KA. Recent advances in the imaging of frontotemporal dementia. Curr Neurol Neurosci Rep. (2012) 12:715-23. doi: 10.1007/s11910-012-0317-0

132. Sabater L, Gaig C, Gelpi E, Bataller L, Lewerenz J, Torres-Vega E, et al. A novel non-rapid-eye movement and rapid-eye-movement parasomnia with sleep breathing disorder associated with antibodies to IgLON5: a case series, characterisation of the antigen, and post-mortem study. Lancet Neurol. (2014) 13:575-86. doi: 10.1016/S1474-4422(14)70051-1

133. Gaig C, Iranzo A, Santamaria J, Graus F. The sleep disorder in anti-lgLON5 disease. Curr Neurol Neurosci Rep. (2018) 18:41. doi: 10.1007/s11910-018-0848-0

134. Gaig C, Compta Y. Neurological profiles beyond the sleep disorder in patients with anti-IgLON5 disease. Curr Opin Neurol. (2019) 32:493-99. doi: 10.1097/WCO.0000000000000677

135. Tao Q, Wei Q, Song S, Yin X. Motor neuron disease-like phenotype associated with anti-IgLON5 disease. CNS Neurosci Ther. (2018) 24:1305-8. doi: $10.1111 / \mathrm{cns} .13038$

136. Schöberl F, Levin J, Remi J, Goldschagg N, Eren O, Okamura N, et al. IgLON5: a case with predominant cerebellar tau deposits and leptomeningeal inflammation. Neurology. (2018) 91:180-2. doi: 10.1212/WNL.0000000000005859

137. Peeters I, Wiels W, De Raedt S, Flamez A. Unusual head movements in anti-IgLON5 disease. Mov Disord Clin Pract. (2020) 7:708-9. doi: $10.1002 / \mathrm{mdc} 3.13016$

138. Nissen MS, Blaabjerg M. Anti-IgLON5 disease: a case with 11-year clinical course and review of the literature. Front Neurol. (2019) 10:1056. doi: 10.3389/fneur.2019.01056

139. Fesharaki-Zadeh A. Chronic traumatic encephalopathy: a brief overview. Front Neurol. (2019) 10:713. doi: 10.3389/fneur.2019.00713

140. Gardner A, Iverson GL, McCrory P. Chronic traumatic encephalopathy in sport: a systematic review. Br J Sports Med. (2014) 48:84-90. doi: 10.1136/bjsports-2013-092646

141. Jordan BD. The clinical spectrum of sport-related traumatic brain injury. Nat Rev Neurol. (2013) 9:222-30. doi: 10.1038/nrneurol.2013.33

142. Katsumoto A, Takeuchi H, Tanaka F. Tau pathology in chronic traumatic encephalopathy and Alzheimer's disease: similarities and differences. Front Neurol. (2019) 10:980. doi: 10.3389/fneur.2019.00980

143. Falcon B, Zivanov J, Zhang W, Murzin AG, Garringer HJ, Vidal R, et al. Novel tau filament fold in chronic traumatic encephalopathy encloses hydrophobic molecules. Nature. (2019) 568:420-3. doi: 10.1038/s41586-019-1026-5

144. DeTure MA, Dickson DW. The neuropathological diagnosis of Alzheimer's disease. Mol Neurodegener. (2019) 14:32. doi: 10.1186/s13024-019-0333-5

145. Atri A. The Alzheimer's disease clinical spectrum. Med Clin North Am. (2019) 103:263-93. doi: 10.1016/j.mcna.2018.10.009

146. McKhann GM, Knopman DS, Chertkow H, Hyman BT, Jack CR, Kawas $\mathrm{CH}$, et al. The diagnosis of dementia due to Alzheimer's disease: recommendations from the National Institute on Aging-Alzheimer's Association workgroups on diagnostic guidelines for Alzheimer's disease. Alzheimers Dement. (2011) 7:263-9. doi: 10.1016/j.jalz.2011.03.005

147. Jack CR, Bennett DA, Blennow K, Carrillo MC, Dunn B, Haeberlein $\mathrm{SB}$, et al. NIA-AA Research Framework: Toward a biological definition of Alzheimers disease. Alzheimers Dement. (2018) 14:535-62. doi: 10.1016/j.jalz.2018.02.018

148. Kurlan R, Richard IH, Papka M, Marshall F. Movement disorders in Alzheimers disease: more rigidity of definitions is needed. Mov Disord. (2000) 15:24-9. doi: 10.1002/1531-8257(200001)15:1<24::AID-MDS1006>3 $0 . \mathrm{CO} ; 2-\mathrm{X}$

149. Starkstein SE, Merello M. Movement disorders in Alzheimer's disease. In: Merello M, Starkstein SE, editors. Movement Disorders in Dementias. London: Springer London (2014). pp. 129-40.

150. Pavlis CJ, Kutscher EC, Carnahan RM, Kennedy WK, Van Gerpen S, Schlenker E. Rivastigmine-induced dystonia. Am J Heal Pharm. (2007) 64:2468-70. doi: 10.2146/ajhp060399

151. Magnuson TM, Roccaforte WH, Wengel SP, Burke WJ. Medication-induced dystonias in nine patients with dementia. J Neuropsychiatry Clin Neurosci. (2000) 12:219-25. doi: 10.1176/jnp.12.2.219

152. van den Bosch S, Bouckaert F, Peuskens J. Mirtazapine-induced dystonia in a patient with Alzheimer's disease. Tijdschr Psychiatr. (2006) 48:153-7. 
153. Vanacore N, Suzzareddu G, Maggini M, Casula A, Capelli P, Raschetti R. Pisa syndrome in a cohort of Alzheimer's disease patients. Acta Neurol Scand. (2005) 111:199-201. doi: 10.1111/j.1600-0404.2005.00388.x

154. Cossu G, Melis M, Melis G, Maccioni E, Putzu V, Catte O, et al. Reversible Pisa syndrome (pleurothotonus) due to the cholinesterase inhibitor galantamine: case report. Mov Disord. (2004) 19:1243-4. doi: $10.1002 / \mathrm{mds} .20164$

155. Mimura Y, Kurose S, Takata T, Tabuchi H, Mimura M, Funayama M. Pisa syndrome induced by switching of a choline-esterase inhibitor treatment from donepezil to galantamine: a case report. BMC Neurol. (2020) 20:183. doi: 10.1186/s12883-020-01769-2

156. Caviness JN. Myoclonus and neurodegenerative disease-what's in a name? Parkinsonism Relat Disord. (2003) 9:185-92. doi: 10.1016/S1353-8020(02)00054-8

157. Wilkins DE, Hallett M, Erba G. Primary generalised epileptic myoclonus: a frequent manifestation of minipolymyoclonus of central origin. J Neurol Neurosurg Psychiatry. (1985) 48:506-16. doi: 10.1136/jnnp.48.6.506

158. Silveira-Moriyama L, Lees AJ. Endemic atypical parkinsonism. J Neurol Sci. (2018) 388:220-1. doi: 10.1016/j.jns.2018.02.018

159. Caparros-Lefebvre D, Sergeant N, Lees A, Camuzat A, Daniel S, Lannuzel A, et al. Guadeloupean Parkinsonism: a cluster of progressive supranuclear palsy-like tauopathy. Brain. (2002) 125:801-11. doi: 10.1093/brain/awf086

160. Steele JC. Parkinsonism-dementia complex of Guam. Mov Disord. (2005) 20:S99-S107. doi: 10.1002/mds.20547

161. Okumiya K, Wada T, Fujisawa M, Ishine M, Garcia del Saz E, Hirata Y, et al. Amyotrophic lateral sclerosis and parkinsonism in Papua, Indonesia: 2001-2012 survey results. BMJ Open. (2014) 4:e004353. doi: 10.1136/bmjopen-2013-004353

162. Kokubo Y, Ito K, Kuzuhara S. Ophthalmomyiasis-like pigmentary retinopathy in ALS/PDC in the Kii peninsula of Japan. Neurology. (2003) 60:1725-6. doi: 10.1212/01.WNL.0000061487.16841.72

163. Kokubo Y, Kuzuhara S. Neuroradiological study of patients with amyotrophic lateral sclerosis and Parkinsonism-dementia complex on the Kii Peninsula of Japan. Arch Neurol. (2003) 60:1257-61. doi: 10.1001/archneur.60.9.1257

164. Yeo T, Tan LC. 'Hummingbird' Sign in a patient with Guam Parkinsonismdementia complex. J Mov Disord. (2017) 10:145-8. doi: 10.14802/jmd.17025

165. Mimuro M, Yoshida M, Kuzuhara S, Kokubo Y. Amyotrophic lateral sclerosis and parkinsonism-dementia complex of the Hohara focus of the Kii Peninsula: a multiple proteinopathy? Neuropathology. (2018) 38:98-107. doi: $10.1111 /$ neup. 12434

166. Ishiura H, Takahashi Y, Mitsui J, Yoshida S, Kihira T, Kokubo Y, et al. C9ORF72 repeat expansion in amyotrophic lateral sclerosis in the Kii Peninsula of Japan. Arch Neurol. (2012) 69:1154-8. doi: 10.1001/archneurol.2012.1219

167. Dombroski BA, Galasko DR, Mata IF, Zabetian CP, Craig U-K, Garruto RM, et al. C9orf72 hexanucleotide repeat expansion and guam amyotrophic lateral sclerosis-Parkinsonism-dementia complex. JAMA Neurol. (2013) 70:742. doi: 10.1001/jamaneurol.2013.1817

168. van Bemmel $\mathrm{K}$, van der Weegen $\mathrm{K}$. Universal classifications, national approaches and specific situations: a comparative study on the conceptualization of nodding syndrome in Uganda and Tanzania. Anthropol Med. (2019) 26:177-96. doi: 10.1080/13648470.2017.1361652

169. Spencer PS, Mazumder R, Palmer VS, Pollanen MS. Nodding syndrome phenotypes. Rev Neurol (Paris). (2019) 175:679-85. doi: 10.1016/j.neurol.2019.09.005

170. Idro R, Opoka RO, Aanyu HT, Kakooza-Mwesige A, Piloya-Were T, Namusoke $\mathrm{H}$, et al. Nodding syndrome in Ugandan children-clinical features, brain imaging and complications: a case series. BMJ Open. (2013) 3:e002540. doi: 10.1136/bmjopen-2012-002540

171. Caparros-Lefebvre D, Golbe LI, Deramecourt V, Maurage CA, Huin V, Buée-Scherrer V, et al. A geographical cluster of progressive supranuclear palsy in northern France. Neurology. (2015) 85:1293-300. doi: 10.1212/WNL.00000000000 01997

172. Hoffman LA, Vilensky JA. Encephalitis lethargica: 100 years after the epidemic. Brain. (2017) 140:2246-51. doi: 10.1093/brain/awx177
173. Villemagne VL, Velakoulis D, Doré V, Bozinoski S, Masters CL, Rowe $\mathrm{CC}$, et al. Imaging of tau deposits in adults with Niemann-Pick type C disease: a case-control study. Eur J Nucl Med Mol Imaging. (2019) 46:1132-8. doi: 10.1007/s00259-019-4273-7

174. Ortega-Aznar A, Romero-Vidal FJ, Castellví J, Ferrer JM, Codina A. Adultonset subacute sclerosing panencephalitis: clinico-pathological findings in 2 new cases. Clin Neuropathol. (2003) 22:110-8.

175. Risacher SL, Farlow MR, Bateman DR, Epperson F, Tallman EF, Richardson $\mathrm{R}$, et al. Detection of tau in Gerstmann-Sträussler-Scheinker disease (PRNP F198S) by [18F]Flortaucipir PET. Acta Neuropathol Commun. (2018) 6:114. doi: 10.1186/s40478-018-0608-z

176. Forrest SL, Kril JJ, Stevens CH, Kwok JB, Hallupp M, Kim WS, et al. Retiring the term FTDP-17 as MAPT mutations are genetic forms of sporadic frontotemporal tauopathies. Brain. (2018) 141:521-34. doi: 10.1093/brain/awx328

177. DeJesus-Hernandez M, Mackenzie IR, Boeve BF, Boxer AL, Baker $M$, Rutherford NJ, et al. Expanded GGGGCC hexanucleotide repeat in noncoding region of C9ORF72 causes chromosome 9p-linked FTD and ALS. Neuron. (2011) 72:245-56. doi: 10.1016/j.neuron.2011. 09.011

178. Bourinaris T, Houlden H. C9orf72 and its relevance in Parkinsonism and movement disorders: a comprehensive review of the literature. Mov Disord Clin Pract. (2018) 5:575-85. doi: 10.1002/mdc3.12677

179. Skibinski G, Parkinson NJ, Brown JM, Chakrabarti L, Lloyd SL, Hummerich $\mathrm{H}$, et al. Mutations in the endosomal ESCRTIII-complex subunit CHMP2B in frontotemporal dementia. Nat Genet. (2005) 37:806-8. doi: $10.1038 /$ ng 1609

180. Van Langenhove T, van der Zee J, Sleegers K, Engelborghs S, Vandenberghe R, Gijselinck I, et al. Genetic contribution of FUS to frontotemporal lobar degeneration. Neurology. (2010) 74:366-71. doi: 10.1212/WNL.0b013e3181 ccc732

181. Goldman JS, Rademakers R, Huey ED, Boxer AL, Mayeux R, Miller $\mathrm{BL}$, et al. An algorithm for genetic testing of frontotemporal lobar degeneration. Neurology. (2011) 76:475-83. doi: 10.1212/WNL.0b013e3182 0a0d13

182. Rohrer JD, Warren JD, Omar R, Mead S, Beck J, Revesz T, et al. Parietal lobe deficits in frontotemporal lobar degeneration caused by a mutation in the progranulin gene. Arch Neurol. (2008) 65:506. doi: 10.1001/archneur.65.4.506

183. Le Ber I, Camuzat A, Hannequin D, Pasquier F, Guedj E, Rovelet-Lecrux A, et al. Phenotype variability in progranulin mutation carriers: a clinical, neuropsychological, imaging and genetic study. Brain. (2008) 131:732-746. doi: 10.1093/brain/awn012

184. Rohrer JD, Ridgway GR, Modat M, Ourselin S, Mead S, Fox NC, et al. Distinct profiles of brain atrophy in frontotemporal lobar degeneration caused by progranulin and tau mutations. Neuroimage. (2010) 53:1070-6. doi: 10.1016/j.neuroimage.2009.12.088

185. Kim EJ, Rabinovici GD, Seeley WW, Halabi C, Shu H, Weiner MW, et al. Patterns of MRI atrophy in tau positive and ubiquitin positive frontotemporal lobar degeneration. J Neurol Neurosurg Psychiatry. (2007) 78:1375-8. doi: 10.1136/jnnp.2006.114231

186. Josephs KA, Whitwell JL, Parisi JE, Petersen RC, Boeve BF, Jack Jr CR, et al. Caudate atrophy on MRI is a characteristic feature of FTLD-FUS. Eur $J$ Neurol. (2010) 17:969-75. doi: 10.1111/j.1468-1331.2010.02975.x

187. Caroppo P, Le Ber I, Camuzat A, Clot F, Naccache L, Lamari F, et al. Extensive white matter involvement in patients with frontotemporal lobar degeneration. JAMA Neurol. (2014) 71:1562. doi: 10.1001/jamaneurol.2014.1316

188. Rohrer JD, Nicholas JM, Cash DM, van Swieten J, Dopper E, Jiskoot L, et al. Presymptomatic cognitive and neuroanatomical changes in genetic frontotemporal dementia in the Genetic Frontotemporal dementia Initiative (GENFI) study: a cross-sectional analysis. Lancet Neurol. (2015) 14:253-62. doi: 10.1016/S1474-4422(14)70324-2

189. Schönecker S, Neuhofer C, Otto M, Ludolph A, Kassubek J, Landwehrmeyer $\mathrm{B}$, et al. Atrophy in the thalamus but not cerebellum is specific for C9orf72 FTD and ALS patients - an atlas-based volumetric MRI study. Front Aging Neurosci. (2018) 10:45. doi: 10.3389/fnagi.2018.00045 
190. Lynch T, Sano M, Marder KS, Bell KL, Foster NL, Defending RF, et al. Clinical characteristics of a family with chromosome 17-linked disinhibitiondementia- parkinsonism-amyotrophy complex. Neurology. (1994) 44:18788. doi: 10.1212/WNL.44.10.1878

191. McCarthy A, Lonergan R, Olszewska DA, O’Dowd S, Cummins G, Magennis B, et al. Closing the tau loop: the missing tau mutation. Brain. (2015) 138:3100-9. doi: 10.1093/brain/awv234

192. Kouri N, Carlomagno Y, Baker M, Liesinger AM, Caselli RJ, Wszolek $\mathrm{ZK}$, et al. Novel mutation in MAPT exon 13 (p.N410H) causes corticobasal degeneration. Acta Neuropathol. (2014) 127:271-82. doi: 10.1007/s00401-013-1193-7

193. Baba Y, Baker MC, Le Ber I, Brice A, Maeck L, Kohlhase J, et al. Clinical and genetic features of families with frontotemporal dementia and Parkinsonism linked to chromosome 17 with a P301S tau mutation. J Neural Transm. (2007) 114:947-50. doi: 10.1007/s00702-007-0632-9

194. Rossi G, Marelli C, Farina L, Laurà M, Maria Basile A, Ciano C, et al. The G389R mutation in the MAPT gene presenting as sporadic corticobasal syndrome. Mov Disord. (2008) 23:892-5. doi: 10.1002/mds.21970
195. Tacik P, DeTure M, Lin W-L, Sanchez Contreras M, Wojtas A, Hinkle $\mathrm{KM}$, et al. A novel tau mutation, p.K317N, causes globular glial tauopathy. Acta Neuropathol. (2015) 130:199-. doi: 10.1007/s00401-0151425-0

196. Didonna A. Tau at the interface between neurodegeneration and neuroinflammation. Genes Immun. (2020) doi: 10.1038/s41435-020-00113-5. [Epub ahead of print].

Conflict of Interest: The authors declare that the research was conducted in the absence of any commercial or financial relationships that could be construed as a potential conflict of interest.

Copyright (c) 2020 Ganguly and Jog. This is an open-access article distributed under the terms of the Creative Commons Attribution License (CC BY). The use, distribution or reproduction in other forums is permitted, provided the original author(s) and the copyright owner(s) are credited and that the original publication in this journal is cited, in accordance with accepted academic practice. No use, distribution or reproduction is permitted which does not comply with these terms. 